OPEN ACCESS

Edited by:

Antonio Salgado,

University of Minho, Portugal

Reviewed by:

Beklem Bostancioglu,

Karolinska Institute, Sweden

Sina Naserian,

Hôpital Paul Brousse, France

${ }^{*}$ Correspondence:

Mauro Krampera

mauro.krampera@univr.it

Specialty section:

This article was submitted to

Stem Cell Research,

a section of the journal

Frontiers in Cell and Developmental

Biology

Received: 18 August 2020 Accepted: 20 October 2020 Published: 06 November 2020

Citation:

Bazzoni R, Takam Kamga P, Tanasi I and Krampera M (2020) Extracellular Vesicle-Dependent

Communication Between

Mesenchymal Stromal Cells

and Immune Effector Cells.

Front. Cell Dev. Biol. 8:596079. doi: 10.3389/fcell.2020.596079

\section{Extracellular Vesicle-Dependent Communication Between Mesenchymal Stromal Cells and
Immune Effector Cells}

\author{
Riccardo Bazzoni', Paul Takam Kamga ${ }^{1,2}$, llaria Tanasi' and Mauro Krampera ${ }^{\text {* }}$ \\ 1 Stem Cell Research Laboratory, Section of Hematology, Department of Medicine, University of Verona, Verona, Italy, \\ ${ }^{2}$ EA4340-BCOH, Biomarker in Cancerology and Onco-Haematology, UVSQ, Université Paris Saclay, Boulogne-Billancourt, \\ France
}

Mesenchymal stem/stromal cells (MSCs) are multipotent cells residing in the stromal tissues of the body and capable of promoting tissue repair and attenuating inflammatory processes through their immunomodulatory properties. Preclinical and clinical observations revealed that not only direct intercellular communication mediates MSC properties; in fact, a pivotal role is also played by the release of soluble and bioactive factors, such as cytokines, growth factor and extracellular vesicles (EVs). EVs are membrane-coated vesicles containing a large variety of bioactive molecules, including lipids, proteins, and nucleic acids, such as RNA. EVs release their contents into target cells, thus influencing cell fate through the control of intracellular processes. In addition, MSC-derived EVs can mediate modulatory effects toward different effector cells belonging to both innate and adaptive immunity. In this review, we will discuss the literature data concerning MSC-derived EVs, including the current standardized methods for their isolation and characterization, the mechanisms supporting their immunoregulatory properties, and their potential clinical application as alternative to MSC-based therapy for inflammatory reactions, such as graft-versus-host disease (GvHD).

\footnotetext{
Keywords: extracellular vesicles, exosomes, microvesicles, mesenchymal stromal cells, immune effector cells, immunomodulation
}

\section{INTRODUCTION}

Mesenchymal stromal cells (MSCs) are multipotent stem cells of mesodermal origin described in bone marrow (BM) for the first time by Alexander Friedenstein in 1966 (Friedenstein et al., 1966). Over the last decades, MSCs were also identified in a large number of tissues, including fat, umbilical cord, amniotic fluid, placenta, skin, dental pulp, and many others (Riekstina et al., 2008; Marquez-Curtis et al., 2015; Camilleri et al., 2016; Ventura Ferreira et al., 2018; Caseiro et al., 2019; Fukutake et al., 2019). In 2006, the International Society for Cellular Therapy (ISCT) established the minimal criteria to define human MSCs, i.e., (i) plastic-adherence when maintained in standard culture conditions; (ii) surface expression of CD105, CD73 and CD90 antigens while lacking CD45, CD34, CD14 or CD11b, CD79 $\alpha$ or CD19, and HLA-DR molecules; (iii) in vitro differentiation into three mesodermal lineages (osteoblasts, adipocytes, and chondrocytes) (Dominici et al., 2006). 
MSCs boosted a great interest in the field of regenerative medicine and tissue engineering thanks to their ability to promote tissue regeneration and to modulate immune response (de Mayo et al., 2017; Petri et al., 2017; Pokrywczynska et al., 2019). Indeed, MSCs possess broad immunomodulatory properties affecting immune effector cells of both innate and adaptive responses (Krampera, 2011). For example, MSCs are capable of stimulating cytokine release and proliferation of innate lymphoid cells (van Hoeven et al., 2018), affecting dendritic cell (DC) maturation and activation (Zhang et al., 2004), suppressing natural killer $(\mathrm{NK})$ cell activity and proliferation (Spaggiari et al., 2008), supporting the expansion of myeloid-derived suppressor cells (MDSCs) (Yen et al., 2013), and regulating B cell proliferation and activation (Fan et al., 2016) as well as $\mathrm{T}$ cell activity, balance between $\mathrm{T}$ helper (Th)1 and Th2 lymphocytes and expansion of $\mathrm{T}$ regulatory (Treg) cells (Haddad and Saldanha-Araujo, 2014; Gao et al., 2016). The ability of MSCs to modulate the immune response is well documented by several preclinical and clinical studies in a wide range of inflammatory and autoimmune diseases, such as Crohn's disease (Forbes, 2017), rheumatoid arthritis (Ansboro et al., 2017), diabetes (Cho et al., 2018), graft-versus-host disease (GvHD) (Le Blanc et al., 2008), sepsis (Hall et al., 2013), cardiovascular diseases (Bagno et al., 2018), allergic airway inflammation (Takeda et al., 2018), and many others. Initially, the biological activity of MSC was ascribed to their ability to home within the injury site; however, only a small fraction of MSCs is capable of reaching the damaged tissues after systemic administration (Kraitchman et al., 2005; Yukawa et al., 2012; Scarfe et al., 2018), while the majority of them are rapidly cleared through phenomena of efferocytosis, thus polarizing macrophages toward an inhibitory phenotype (Galleu et al., 2017). In addition, MSCs may act at paracrine level through the release of bioactive factors, including transforming growth factor $\beta$ (TGF- $\beta$ ), hepatocyte growth factor, prostaglandin E2 (PGE2), interleukin (IL)-10 and IL-6, human leukocyte antigen G (HLA-G), indoleamine-2,3-dioxygenase (IDO), nitric oxide (NO), and other mediators (Sato et al., 2006; Ryan et al., 2007; Németh et al., 2009; Bouffi et al., 2010; Du et al., 2016; Wang et al., 2018; Liu et al., 2019; Lu et al., 2019; Pittenger et al., 2019). In the last years, membrane-bound particles, known as extracellular vesicles (EVs), have been recognized as an important MSC paracrine factor in addition to soluble factors (Chen et al., 2016; Bier et al., 2018). EVs represent a very effective, physiological intercellular communication, even at low molecule concentrations at which soluble factors could be rapidly inactivated. Strong experimental evidence shows that MSC-EVs are capable of recapitulating the immunomodulation of their parental cells (Rani et al., 2015; Seo et al., 2019). Therefore, in this review we will provide an overview of the literature data supporting the MSC-EV-dependent communication between MSCs and immune effector cells (IECs).

\section{CHARACTERIZATION OF EVs}

EVs consist of a phospholipid bilayer envelope acting as molecular shuttle for various molecules, such as proteins, different types of nucleic acids, lipids and active metabolites (Lai et al., 2016; Yuan et al., 2017; Yang et al., 2018; Shojaati et al., 2019). Historically, EVs are classified into three main groups according to their biogenesis and size: (i) exosomes, (ii) microvesicles and (iii) apoptotic bodies. Exosomes (diameter range $50-100 \mathrm{~nm}$ ) represent the smallest $\mathrm{EV}$ fraction deriving from the fusion of intracellular endosomes with plasma membrane, followed by their release into the extracellular space (Stephen et al., 2016). The production of exosomes is generally constitutive, although it can increase upon cell stimulation (Fierabracci et al., 2015). Microvesicles (MVs; diameter range $100-1,000 \mathrm{~nm}$ ) are generated by cytoplasmic membrane budding in response to several stimuli resulting in cytosolic $\mathrm{Ca}^{2+}$ increment and disassembly of the cytoskeleton (Ratajczak et al., 2006). Apoptotic bodies (diameter range 1$5 \mu \mathrm{m}$ ) are characterized by irregular shapes and heterogenous sizes (Caruso and Poon, 2018). Apoptotic bodies are functionally different, as they are released during apoptosis and contain mainly cellular debris, such as micronuclei, chromatin remnants and cytosol portions (Battistelli and Falcieri, 2020). As several studies were performed with different separation approaches and cellular sources of EVs, it is still not possible to propose a specific classification of different EV subtypes as well as specific markers and biogenesis processes (Gould and Raposo, 2013; Cocucci and Meldolesi, 2015). Consequently, the Minimal Information of Studies of Extracellular Vesicles 2018 (MISEV2018) suggests to use the generic terms "small/medium/large EVs", according to their size or density, instead of the classical "exosomes," "microvesicles," and "apoptotic bodies" terms (Théry et al., 2018). According to MISEV2018, to confirm the nature of EVs and the degree of purity of EV preparation, the scientific community has encouraged to evaluate the presence of at least one of transmembrane or GPI-anchored proteins associated to plasma membrane and/or endosomes (for example tetraspanins, integrins, and MHC class I) and cytosolic proteins recovered in EVs (for example lipid or membrane protein-binding ability like ESCRT-I/II/III and ALIX or promiscuous proteins like HSP70 or cytoskeleton proteins like actin and tubulin) and major components of non-EV co-isolated structures (for example lipoproteins, protein/nucleic acid aggregates, and ribosomal proteins) (Théry et al., 2018). Additionally, for studies focused on one or more EV subtypes is recommended to assess the presence of transmembrane, lipid-bound and soluble proteins associated to other intracellular compartments than plasma membrane/endosomes, including lamin $\mathrm{A} / \mathrm{C}$, cytochrome $\mathrm{C}$, calnexin, and ATG9A, whereas for the evaluation of EV functional activities, the identification of functional soluble factor in EVs like cytokines, growth factors, adhesion and extracellular matrix proteins is required (Théry et al., 2018).

The communication system based on EVs is highly conserved among the three different animal reigns, thus suggesting how EVs are crucial for intercellular communication (Deatherage and Cookson, 2012; Gill et al., 2019). EVs contribute to cell-to-cell communication via direct contact with target cells through a ligand-receptor interaction. In particular, EVs can transfer information to target cells either without delivering their content or acting like biological shuttles that release their 
cargo into acceptor cells. A classic example of EV contribution to intercellular communication without deliver their content resides in those vesicles that harbor MHC molecules on their surface, thus activating $\mathrm{T}$ cell receptors on $\mathrm{T}$ cells (Raposo et al., 1996; Martin et al., 2014). Concerning the delivery of EV content, EVs can be taken up by target cells through several mechanisms, including clathrin-mediated endocytosis, caveolindependent endocytosis, macropinocytosis, phagocytosis, lipid rafts, and cell surface membrane fusion (Feng et al., 2010; Montecalvo et al., 2012; Svensson et al., 2013; Tian et al., 2014; Costa Verdera et al., 2017; Rai and Johnson, 2019). Although numerous receptors/ligands are implicated into EV uptake including tetraspanins, integrins, immunoglobulins, lectins, and proteoglycans (Morelli et al., 2004; Hao et al., 2007; Barrès et al., 2010; Christianson et al., 2013), to date it is still debated whether EV uptake is a cell-type specific process or not. Indeed, some studies suggest that EVs from different sources can be taken up by every cell type (Costa Verdera et al., 2017; Horibe et al., 2018), whereas others report that only a particular combination of EV and target cells (and thus the right association between receptors and ligands) allow the EV uptake by acceptors cells (Fitzner et al., 2011; Zech et al., 2012; Chivet et al., 2014; Di Trapani et al., 2016). Finally, recent evidence suggested that nanotubes could synergistically act with EVs in intercellular communication, as microsized particles could be transferred into target cells via nanotubes (Ware et al., 2015; Nawaz and Fatima, 2017).

As EVs reflect the characteristics of their cells of origin both at molecular and functional level, EVs have emerged as a novel potential therapeutic approach due to their ability to influence various biological processes, including immune response, cell proliferation, tissue regeneration, cell invasiveness, tubule formation, angiogenesis, synapsis plasticity, and many others (Zaborowski et al., 2015; Silva et al., 2017; Prada et al., 2018; Lee et al., 2019; Mou et al., 2019).

\section{MSC-EVs AND IMMUNOMODULATION}

MSC-EVs play a pivotal role in mediating the paracrine effects of MSCs on immune system. Generally, MSC-EVs may promote an immunosuppressive response through the induction of immature DCs, the polarization of macrophages toward M2-like phenotype, the inhibition of immunoglobulin (Ig) release, the expansion of Tregs and the secretion of anti-inflammatory cytokines (Budoni et al., 2013; Burrello et al., 2016; Favaro et al., 2016; Balbi et al., 2017; Du et al., 2018). However, MSC-EVs should be considered in the whole contest of MSC secretome, because in some experimental settings the immunomodulation mediated by MSC-EVs can only poorly recapitulate the immune properties of their parental cells (Conforti et al., 2014; Gouveia de Andrade et al., 2015; Ma et al., 2019). In the next sections we will try to give a comprehensive overview of the effects of MSCEVs on the innate (macrophages, DCs and NK cells) and adaptive ( $\mathrm{B}$ and $\mathrm{T}$ cells) immune system. As the studies here reported employed different EV subtypes obtained from several MSC sources (BM, umbilical cord, adipose tissue, fetal liver) of different animal species (human, mouse and rat) with several isolation methods, we will refer to them with the generic term "MSC-EVs." The immunomodulatory effects of MSCEVs on innate and adaptive immune system are summarized in Figure 1.

\section{MSC-EVs and Innate Immune System Macrophages}

Macrophages are mononuclear phagocytes with important roles in physiological conditions and in first-line immune response (Zhang and Wang, 2014). Macrophages are extremely plastic cells, with the capability of differentiating into two activated subtypes, i.e., M1 and M2. M1 macrophages are classical activated cells secreting large amount of pro-inflammatory factors, such as TNF- $\alpha$, IL- $1 \beta$ and reactive oxygen species. On the other hand, M2 macrophages are alternatively activated and anti-inflammatory cells producing IL-10 and trophic factors (Shapouri-Moghaddam et al., 2018). Recent data support a contribution of MSC-EVs in modulating the M1/M2 balance, although the precise mechanism remains unclear. For instance, MSC-EVs may hamper the activation of pro-inflammatory M1 macrophages in favor of pro-resolving M2 macrophages that parallel with VEGF-A, IFN$\gamma$, IL-12, and TNF- $\alpha$ reduction as well as IL-10 upregulation (Balbi et al., 2017; Cosenza et al., 2017; Cao et al., 2019). The modulation of several signaling pathways mediated by MSC-EVs may be responsible for this effect. For instance, the inhibition of JAK/STAT signaling was confirmed by many studies, resulting in Arg1 increment and inflammation reduction (Zhao et al., 2018; Cao et al., 2019). The activation of S1P/SK1/S1PR1 signaling by MSC-EVs promotes M2 differentiation through the downregulation of NF- $\kappa$ B-p65 and TGF- $\beta 1$ expression in macrophages, thus restoring cardiac activity after myocardial infarction (Deng et al., 2019). Furthermore, lipopolysaccharide (LPS)-primed MSC-EVs support M2 macrophage polarization, by interfering with LPS-dependent $\mathrm{NF}-\kappa \mathrm{B}$ signaling, and partly activate the AKT1/AKT2 signaling pathway, by attenuating the post-infarction inflammation and cardiomyocyte apoptosis (Xu et al., 2019). An interesting mechanism by which MSC-EVs exert their anti-inflammatory function is the M2 polarization through MSC-EV-mediated mitochondrial transfer that is dependent on macrophage oxidative phosphorylation (Morrison et al., 2017). In parallel, in response to oxidative stress, MSCs outsource mitochondria depolarized by MVs, thus enhancing macrophage bioenergetics (Phinney et al., 2015) and therefore their proinflammatory features (Tavakoli et al., 2013). Moreover, MSCsEVs may trigger the anti-inflammatory phenotype and proresolving properties of mature, human regulatory macrophages, a subclass of M2 macrophages characterized by modest IL22 and IL-23 production and PGE2 hyper-expression, thus leading to reduction of Th17 response (Hyvärinen et al., 2018). MSC-EVs can also reduce chemokine expression (CXCL1 and CCL5) that are necessary for inflammatory response by macrophages (Zou et al., 2014; Willis et al., 2017). Interestingly, MSC-EVs express CCR2 chemokine, bind and reduce the concentration of the free pro-inflammatory CCL2 ligand, and therefore prevent the activation and recruitment of M1 macrophages (Shen et al., 2016). MSC-EVs may also trigger the 


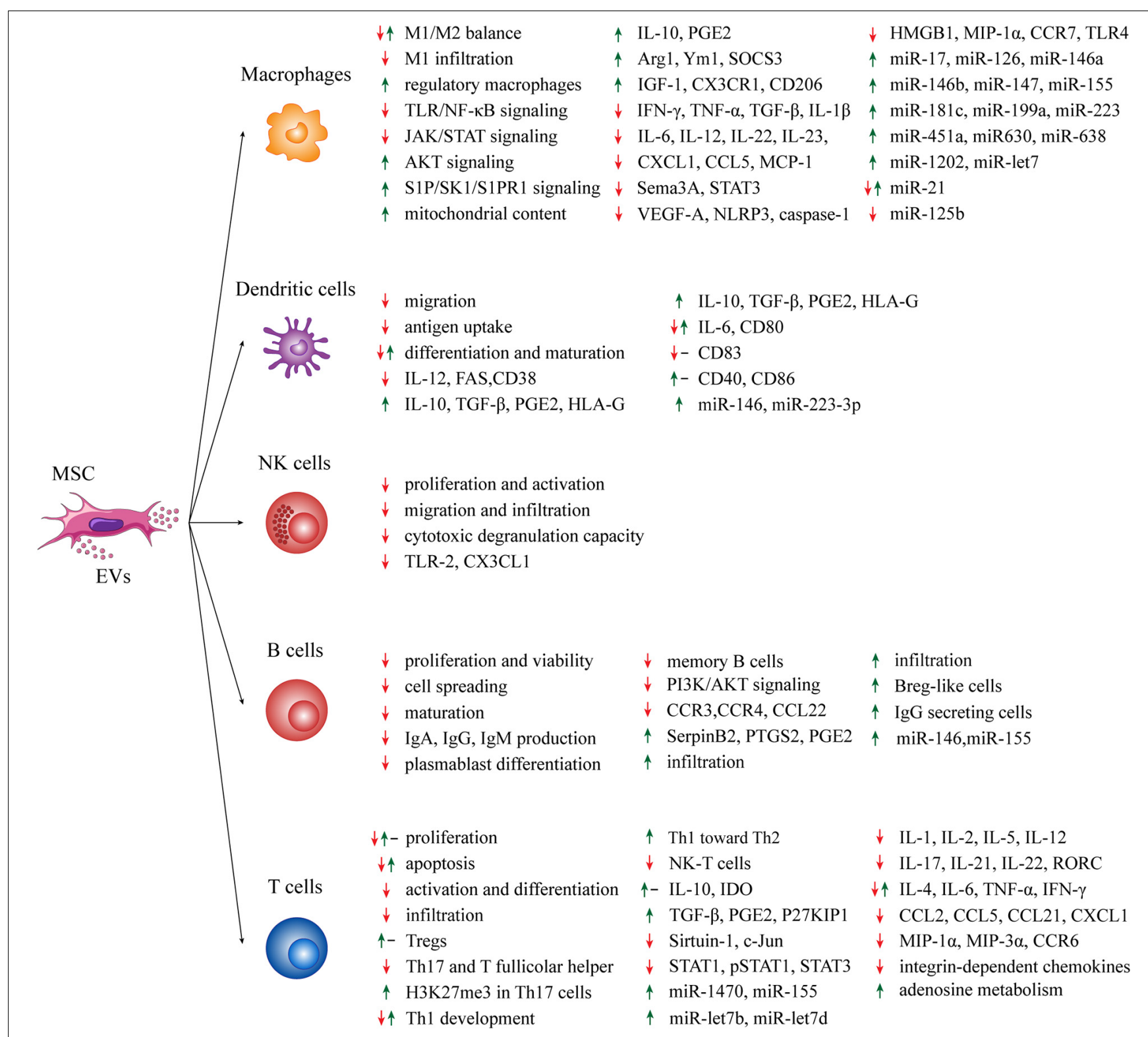

FIGURE 1 | Summary of the effects of MSC-EVs on immune effector cells. Green arrows: positive effect; red arrows: negative effect; black dashes: no effect.

anti-inflammatory phenotype in hepatic macrophages through IGF-1 (Fiore et al., 2020).

Several miRNAs are involved into MSC-EV-mediated antiinflammatory effects on M1/M2 balance. For instance, miR223 overexpression in MSC-EVs may reprogram macrophages from M1 to M2 phenotype by targeting Sema3A and STAT3 (Wang et al., 2015; He et al., 2019). Under hypoxic condition, the enrichment of miR-223 determines the overexpression of miR-146b, miR-126 and miR-199a, which in turn upregulate the expression of Arg1 and Yml and promote the antiinflammatory M2 state (Lo Sicco et al., 2017). Other miRNAs involved in M2 polarization are miR-155 and miR-21, whose downregulation results in the increase of SOCS3 and M2 molecules (IL-10, CD206 and arginase) as well as M1 marker reduction (CCR7, IL-1 $\beta$, IL-6, and NO) (Henao Agudelo et al., 2017). IL-1 $\beta$-primed MSC-EVs express high levels of miR-146a promoting M2 macrophage polarization more effectively than IL-1 $\beta$-primed MSC, thus increasing survival of septic mice (Song et al., 2017). The comparative miRNA analysis of EVs isolated from either IFN- $\gamma$-primed or resting MSCs revealed that miR-150-5p, whose target genes is involved in acute-phase response and signaling in macrophages, is downregulated in IFN- $\gamma$-primed EVs. Nevertheless, no difference between primed and resting EVs has been observed in promoting macrophage differentiation toward M2 phenotype (Marinaro et al., 2019). The enrichment of miR-let7 within MSC-EVs may favor M2 polarization and suppress macrophage infiltration through miRlet7/HMGA2/NF-кB pathway and miR-let7/IGF2BP1/PTEN 
pathway, respectively ( $\mathrm{Li}$ et al., 2019). Moreover, LPS-primed MSC-EVs regulate the M1/M2 macrophage balance more efficiently than resting EVs, thanks to the expression of miR-let7b, which inhibits TLR4/NF- $\mathrm{B} / \mathrm{STAT} 3 / \mathrm{AKT}$ signaling pathway, thus hampering inflammation and enhancing diabetic cutaneous wounds healing (Ti et al., 2015). TLR/NF- $\mathrm{KB}$ signaling can be targeted by other miRNAs too. In a model of burn-induced inflammation, the administration of MSC-EVs overexpressing miR-181c reduced the number of macrophages (and neutrophils) potentially inhibiting TLR4 expression and its downstream target proteins NF- $\mathrm{B} / \mathrm{P} 65$ and p-65, thus preventing inflammation ( $\mathrm{Li}$ et al., 2016). MSC-EV fraction is characterized by the enrichment in miR-451a, miR-1202, miR-630, and miR-638 and the reduced expression of miR-125b and miR-21. This miRNA profile may be responsible for targeting MYD88-dependent inflammatory nodes to suppress TLR/NF- $\mathrm{B}$ signaling pathway and macrophage activation (Phinney et al., 2015). Additionally, Zhang et al. found in vitro that MSC-EVs induce monocytes to switch toward an anti-inflammatory M2-phenotype via MYD88-dependent TLR signaling pathway, resulting in a reduction of IL-1 $\beta$, IL-6, IL-12, and TNF- $\alpha$ levels and higher IL-10 concentration, thus polarizing activated $\mathrm{CD}^{+}{ }^{+} \mathrm{T}$ cells toward Treg subset (Zhang et al., 2013).

MSC-EVs also prevent M1-type macrophage infiltration in injury sites by lowering MCP-1, CCL5, HMGB1, and MIP-1 $\alpha$ expression (Yu et al., 2016; Spinosa et al., 2018; Woo et al., 2020), probably through miR-147 expression (Spinosa et al., 2018). Interestingly, in a model of thioglycolate-induced peritonitis, treatment with MSC-EVs reduced macrophage infiltration in the peritoneal cavity by inducing a M2-like regulatory phenotype; this effect was partially associated to the upregulation of CX3CR1 in $\mathrm{F} 4 / 80^{+} / \mathrm{Ly}_{6 \mathrm{C}}+\mathrm{CCR}^{+}$macrophage subset (Henao Agudelo et al., 2017). Concerning the homing ability of MSC-EVs, Lankford et al. demonstrated in a model of damaged spinal cord that MSC-EVs can migrate only in the injury site and M2-type macrophage are the primary target of EVs (Lankford et al., 2018).

Finally, MSC-EVs mediate miR-17 transfer from parental cells to macrophages, thus suppressing NLRP3 inflammasome activation, and consequently caspase-1, IL-1 $\beta$, and IL-6, by targeting TXNIP (Liu et al., 2018). The suppression of NLRP3, caspase-1, IL-1 $\beta$, and IL- 6 was also reported by other authors (Jiang et al., 2019). On the other hand, EVs isolated from LPS-primed periodontal ligament stem cells (characterized by MSC-like markers) may induce strong M1-type polarization in association with pro-inflammatory molecules (TNF- $\alpha$ and IL-6); this effect seems related to double-strand DNA on EV surface (Kang et al., 2018).

\section{Dendritic Cells}

DCs are innate professional antigen-presenting cells (APCs) acting as central regulators of the adaptive immune response. DCs can be found in either resting or active state. Resting DCs are immature APCs expressing low levels of costimulatory molecules (CD38, CD40, CD80, CD83, and CD86) and immunostimulatory cytokines conferring high capacity to capture antigens. DC activation and maturation depend on different stimuli deriving from bacteria, viruses and damaged tissue. Activated DCs are potent $\mathrm{T}$ cell response inducers showing low antigen capture activity and high expression of histocompatibility complex II (MHC class II), costimulatory signals, C-C chemokine receptor type 7 (CCR7) as well as immunostimulatory cytokines (Collin et al., 2013; Patente et al., 2019). EVs secreted by different types of MSCs exert immunosuppressive effects on DCs primarily by inhibiting their activation, eventually leading to the lack of $\mathrm{T}$ cell response triggering. For example, DCs from type 1-diabetic (T1D) patients treated with heterologous MSC-EVs acquired an immature phenotype, characterized by low expression of activation markers and higher production of IL-6, IL-10, TGF$\beta$, and PGE2 (Favaro et al., 2016). Therefore, MSC-EV-treated DCs inhibit the inflammatory $\mathrm{T}$ cell response by decreasing Th17 subset and inducing Foxp3 ${ }^{+}$Tregs (Favaro et al., 2016). Similarly, MSC-EV treatment leads to anergic, IL-10-expressing, regulatory DCs that suppress Th1 and Th17 cell development, but without inducing Tregs (Shigemoto-Kuroda et al., 2017). Notably, MSC-EVs may enhance the release of TGF- $\beta$ and IL10 from $\mathrm{CD}_{11 c^{+}} \mathrm{DCs}$, thus inhibiting lymphocyte proliferation, without affecting the expression of MHC class II, CD86, CD83, and CD40 (Shahir et al., 2020). Upregulation of miR-146 expression in DCs is a possible mechanism by which MSC-EVs promote DC immature phenotype, leading to the downregulation of FAS expression and IL-12 production (Wu et al., 2017). Alternatively, EVs derived from renal, mesenchymal-like cancer stem cells impair dendritic differentiation and $\mathrm{T}$ cell activation by upregulating the expression of the anti-inflammatory molecule HLA-G (Grange et al., 2015). MSC-EVs may also prevent immature DCs from antigen uptake by blocking their maturation (Reis et al., 2018). As a consequence, MSC-EVs lower CD38, CD80, CD83, IL-6, and IL-12 expression, increase the production of the anti-inflammatory cytokine TGF- $\beta$ and reduce DC ability to migrate toward CCL21, the CCR7-ligand, although DCs can still trigger allogeneic $\mathrm{T}$ cell proliferation in vitro (Reis et al., 2018). These MSC-EV-treated DCs resulted enriched of four microRNAs (miR-21-5p, miR-142-3p, miR-223-3p, and miR126-3p) mediating well-known effects on DC maturation and functions (Reis et al., 2018). On the other hand, higher expression of costimulatory factors (CD40, CD80, and CD86), but not MHC class II, can be observed on the surface of murine immature DCs following MSC-EV treatment, thus suggesting that these EVs can mediate the DC maturation required for the induction of effector T-cell (Cho et al., 2019).

\section{Natural Killer Cells}

NK cells are lymphoid cells with a central role in the innate response to viral infections and cancer cells, but recent data suggest that NK cells can also modulate the adaptive immune response involving DCs and T cells, either directly or indirectly (Moretta et al., 2008; Chiossone et al., 2018). Despite a deep search in literature, only a few papers concerning the role of MSC-EVs on NK cell modulation have been found. EVs derived from MSCs. EVs prevent proliferation and IL-2-induced activation of both CD56-dim and CD56-bright NK cells, and suppressed their cytotoxic degranulation in vitro (Fan et al., 2018). In a rat model of experimental autoimmune uveitis (EAU), MSC-EV administration reduces $\mathrm{CD}_{161^{+}} \mathrm{NK}$ cell migration toward eye lesions, thus ameliorating EAU symptoms 
(Bai et al., 2017). The protective and anti-inflammatory effects exerted by MSC-EVs have been also observed in a rat model of renal ischemic reperfusion injury (IRI) and in a renal allografts MHC-disparate rat model, by decreasing both NK cells infiltration and chemokines associated with NK cell recruitment (TLR-2 and CX3CL1) (Koch et al., 2015; Zou et al., 2016). All these immunosuppressive effects seem to be mediated by the expression of TGF- $\beta$ on the EV surface, which induces TGF$\beta /$ Smad downstream pathway (Fan et al., 2018). Other molecules contained in MSC-EVs and associated with anti-inflammatory effects on NK cells are IL-10 and HLA-G (Kordelas et al., 2014). Finally, TNF- $\alpha$ - and IFN- $\gamma$-primed MSC-EVs reduce NK cell proliferation more effectively than resting MSC-EVs (Di Trapani et al., 2016).

\section{MSC-EVs and Adaptive Immune System B Cells}

B cells are lymphoid cells involved in the humoral adaptive immunity through the secretion of antibodies and cytokines (Matsushita, 2019). Among the peripheral blood mononuclear cell (PBMC) subpopulations, B cells show the highest EV uptake (Di Trapani et al., 2016). MSC-EVs may induce in B cells the downregulation of 11 genes (including CCR3, CCR4, and CCL22) and the upregulation of 39 genes (including SerpinB2, PTGS2, and PGE2) involved in immune regulation (Khare et al., 2018). MSC-mediated inhibition of $B$ cell proliferation is more evident following inflammatory priming (Di Trapani et al., 2016). Inflammatory priming induces the increase of miR-155 and miR146 levels within MSC-EVs (Di Trapani et al., 2016). In particular, MSC-EVs induce the downregulation of PI3K/AKT signaling pathway components in B cells, inhibit B cell spreading, and reduce $B$ cell viability via miR-155-5p (Adamo et al., 2019).

Another effect of MSC-EVs on B cells is preventing Ig secretion. MSC-EVs exert a dose-dependent inhibition of IgM, IgG, and IgA production coupled with suppression of B cell proliferation and maturation (Budoni et al., 2013). The reduction of IgG production was also observed by other authors reporting that both MSC-exosomes and microparticles may increase $\mathrm{CD} 19^{+} \mathrm{IL}-10^{+}$Breg-like population and inhibit plasmablast differentiation by transferring TGF- $\beta$, PEG2 and IL1RA (Cosenza et al., 2018). Moreover, MSC-EVs reduce $\mathrm{CD} 27^{+} \mathrm{CD} 19^{+}$memory B cell maturation (Balbi et al., 2017). On the other hand, MSCEVs may sustain, support and enhance the function of human IgG-secreting cells (Nguyen et al., 2018). Notably, MSC-EVs was not capable of significantly affect B cell activation in a strong reactive renal allotransplantation animal model; by contrast, MSC-EVs significantly increased the number of B cells infiltrating the transplanted kidney grafts (Koch et al., 2015). The partial immunomodulation of B cells by MSC soluble factors seems to be preferentially induced by the soluble protein-enriched fraction (PF) rather than by the entire EV-enriched fraction (Carreras-Planella et al., 2019).

\section{T Cells}

$\mathrm{T}$ cells are highly specialized lymphocytes that regulate several aspects of adaptive immunity, such as protection from pathogens, immune surveillance against tumors and alloreaction against non-self-tissues (Kumar et al., 2018). MSCs have a great impact on $\mathrm{T}$ cell functions and therefore potentially on the treatment of numerous $\mathrm{T}$-cell mediated reactive conditions (Duffy et al., 2011).

An efficient approach to suppress $\mathrm{T}$ cell-mediated immune response is preventing $\mathrm{T}$ cell proliferation. Several studies reported that MSC-EVs exert this effect both in vitro and in vivo in several animal models, such as those reproducing myocardium infarction, experimental allergic asthma and renal IRI (Mokarizadeh et al., 2012; Kilpinen et al., 2013; Blazquez et al., 2014; Romani et al., 2015; Teng et al., 2015; de Castro et al., 2017; Monguió-Tortajada et al., 2017; Cosenza et al., 2018; van den Akker et al., 2018; Ji et al., 2019). The inhibition of $\mathrm{T}$ cell proliferation is associated with the reduction or absence of pro-inflammatory cytokines, such as IL-2, IL-6, TNF$\alpha$, and IFN- $\gamma$ (Blazquez et al., 2014; Monguió-Tortajada et al., 2017). Nevertheless, MSC-EVs were capable of increasing T cell number in the graft of a rat renal transplant model for acute rejection associated with the reduction of TNF- $\alpha$ expression and no difference in IL-10 levels (Koch et al., 2015). The inhibition of $\mathrm{T}$ cell proliferation by human MSCs is mostly mediated by the upregulation of indoleamine 2,3-dioxygenase (IDO) (Chinnadurai et al., 2015; Wen et al., 2016); however, controversial results are found when $\mathrm{T}$ cells are treated with MSC-EVs. Some groups reported no significant changes in IDO expression (Del Fattore et al., 2015; Chen et al., 2016), whereas many authors found high concentrations of IDO inside MSCEVs (Romani et al., 2015; Zhang et al., 2018b; Serejo et al., 2019). Other groups reported that MSC-EVs have no effect on $\mathrm{T}$ cell proliferation, but rather promote $\mathrm{T}$ cell apoptosis (Del Fattore et al., 2015; Chen et al., 2016). Conversely, another study reported that MSC-EVs do not alter $\mathrm{T}$ cell viability (Monguió-Tortajada et al., 2017). These different findings suggest that a thorough characterization of MSC-EV content and a standardization of the experimental methods are necessary to foresee the biological effects.

Both $\mathrm{CD}^{+}{ }^{+}$and $\mathrm{CD}^{+}{ }^{+} \mathrm{T}$ cell activation was suppressed by MSC-EVs. At molecular level, the suppression of T cell activation is independent from the antigen presentation due the lack of MHC class I and II as well as other costimulatory molecules on MSC-EV surface (Blazquez et al., 2014; Farinazzo et al., 2018; Dabrowska et al., 2019; Shao et al., 2020). In particular, MSCs constitutively lacking $\beta 2$-microglobulin, a component of HLA-I involved in $\mathrm{CD}^{+} \mathrm{T}$ cell-mediated immune rejection, and the corresponding EVs reduce more efficiently both fibrosis and inflammation in a myocardial infarction animal model compared to the wild-type forms (Shao et al., 2020). The authors reported a greater accumulation of miR-24 in EVs from MSCs constitutively lacking $\beta 2$-microglobulin, which in turn reduces the expression of the apoptotic protein Bim (Shao et al., 2020). Additionally, MSC-EVs can block $\mathrm{CD}^{+}$and $\mathrm{CD}^{+} \mathrm{T}$ cell differentiation toward effector and memory cells, through a mechanism mediated by TGF- $\beta$ signaling, respectively (Blazquez et al., 2014; Álvarez et al., 2018).

Modulation of Treg/Th17 and Th1/Th2 balance has been used to explain the regulatory properties of MSC-EVs on T cells. MSC-EVs may promote induction and expansion of Tregsin 
association with high levels of IL-10 (Mokarizadeh et al., 2012; Kilpinen et al., 2013; Favaro et al., 2014; Del Fattore et al., 2015; Romani et al., 2015; Chen et al., 2016; Nojehdehi et al., 2018; Zhang et al., 2018b; Guo et al., 2019; Ji et al., 2019; Ma et al., 2019), particularly CTLA $-4^{+}, \mathrm{CD} 4^{+} \mathrm{CD} 25^{+} \mathrm{Foxp}^{+}$and Tr1 Treg subpopulations (Chen et al., 2016; Cosenza et al., 2018). Other groups reported no significant changes in Treg number, regardless the higher IL-10 levels after MSC-EV treatment, thus questioning the involvement of Tregs in the upregulation of IL-10 expression by MSC-EVs (Hai et al., 2018). However, the promoting effects of MSC-EVs on Tregs could be partially mediated by their content in TGF- $\beta$ signaling components (Song et al., 2020). Another possible molecular mechanism is the transfer of miR-1470 from MSC-EVs to $\mathrm{CD}^{+} \mathrm{T}$ cells, thus upregulating P27KIP1 expression through c-Jun targeting (Zhuansun et al., 2019). Other miRNAs have been described in this phenomenon, such as miR155-5p, miR-let7b, and miRlet7d. The overexpression in MSC-EVs of miR-155, which targets Sirtuin-1, increases IL-10 and Foxp3 expression in T cells, thus preventing the production of IL-17 and RORC (Zheng et al., 2019). On the other hand, the increase of miR-let7b and miRlet7d may suppress cell proliferation and promote Treg functions, avoiding immune rejection (Wen et al., 2016). Moreover, MSCEV-mediated proliferation and function of CD $4^{+} \mathrm{CD} 25^{+}$Foxp $3^{+}$ Tregs could involve APC-, but not $\mathrm{CD}^{+}{ }^{+} \mathrm{T}$ cell-dependent pathways (Du et al., 2018). Regardless the mechanism mainly involved, other in vivo models, such as experimental type-1 autoimmune diabetes in T1D mice, clearly showed that the induction of Tregs by MSC-EVs can ameliorate histological signs, thus favoring the regeneration of tissues, i.e., pancreatic islets (Nojehdehi et al., 2018).

Concerning other T-cell subsets, there are only a few works so far. For instance, MSC-EVs may prevent Th17 cell development and IL-17 production (Favaro et al., 2014; Chen et al., 2016; Bai et al., 2017; Shigemoto-Kuroda et al., 2017; Hai et al., 2018; Ji et al., 2019; Ma et al., 2019). MSC-EVs may also inhibit Th17 cell differentiation in ulcerative colitis rat models by increasing histone $\mathrm{H} 3 \mathrm{~K} 27 \mathrm{me} 3$ methylation and inhibiting its demethylation, thus suggesting that $\mathrm{H} 3 \mathrm{~K} 27 \mathrm{me} 3$ may be an important target in inflammatory diseases (Chen et al., 2020). Moreover, MSC-EVs can directly prevent Th1 development by promoting Th1 shift toward Th2 cells (Chen et al., 2016; Bai et al., 2017; ShigemotoKuroda et al., 2017; Guo et al., 2019) as well as inhibit T follicular helper cells (Hai et al., 2018). Nevertheless, MSC-EVs can also promote autoreactive, IFN- $\gamma$-secreting memory Th1 cells by functioning in NOD mice as self-antigen carrier and trigger for autoimmunity (Rahman et al., 2014). In addition, the effect of MSC-EVs on natural killer-T (NK-T) cells has been recently described in a rat model of hepatocellular carcinoma; following EV administration, higher percentages of circulating and intratumoral NK-T cells as well as tumors of smaller size and less aggressive were observed as compared to untreated rats (Ko et al., 2015).

Different mechanisms and factors have been described in the immunomodulatory effect of MSC-EVs toward T-cells. The broad and pleiomorphic activity of MSC-EVs reflects their influence on different signaling pathways of T-cells and microenvironmental cells, such as JAK/STAT or NF-kB (Guo et al., 2019). For instance, MSC-EVs can inhibit T-cell infiltration in the injury site of several diseases as well as the production of several chemokines, such as CCL2, CCL5, CCL21, CXCL1, MIP-1 $\alpha$, MIP-3 $\alpha$, and integrin-dependent chemokines) (Cruz et al., 2015; Bai et al., 2017; Shigemoto-Kuroda et al., 2017; Farinazzo et al., 2018; Hai et al., 2018; Dabrowska et al., 2019) and inflammatory molecules, such as IL-1 $\alpha$, IL-1 $\beta$, IL-2, IL-5, IL-12, and IL-17 (Favaro et al., 2014; Chen et al., 2016; de Castro et al., 2017; Shigemoto-Kuroda et al., 2017; Hai et al., 2018; Nojehdehi et al., 2018; Dabrowska et al., 2019; Guo et al., 2019; Ji et al., 2019; Ma et al., 2019). By contrast, anti-inflammatory molecules can be induced by MSC-EVs, such as IL-10, TGF- $\beta$, and PGE2 (Mokarizadeh et al., 2012; Favaro et al., 2014; Del Fattore et al., 2015; Chen et al., 2016; Nojehdehi et al., 2018; Guo et al., 2019; Ji et al., 2019; Ma et al., 2019). Other factors, such as IL-4, IL-6, IFN- $\gamma$, and TNF- $\alpha$, seem to be variably modulated by MSC-EV (Rahman et al., 2014; de Castro et al., 2017; Shigemoto-Kuroda et al., 2017; Hai et al., 2018; Nojehdehi et al., 2018).

Inflammatory priming may enhance the immunomodulatory properties of MSC-EVs. For instance, inflammatory IL$1 \beta$-priming MSC upregulates $\mathrm{PD}-\mathrm{L} 1$ and TGF- $\beta$ expression in EVs, leading to a Treg increment in a mouse model of autoimmune encephalomyelitis (Mokarizadeh et al., 2012). A greater accumulation of TGF- $\beta$ was also reported in IFN- $\gamma$-primed MSC-EVs, which also showed low levels of Galectin-1 and IDO, compared to resting MSC-EVs, leading to a suppression of Treg expansion (Serejo et al., 2019). Compared to resting MSC-EVs, TNF- $\alpha$, and IFN- $\gamma$-primed MSC-EVs reduced more the TNF- $\alpha$ and IFN- $\gamma$ secretion from splenocyte previously activated with lipopolysaccharides and concanavalin A to preferentially stimulate either myeloid cells or $\mathrm{T}$ cells, respectively (Harting et al., 2018). According to the authors, the best efficiency of inflammatory priming was probably due to the higher concentration of COX2 and PGE2 in primed MSC-EVs (Harting et al., 2018). Intriguingly, EVs from MSCs pretreated with a combination of anti- and pro-inflammatory cytokines (TGF- $\beta$ and IFN- $\gamma$, respectively) promote Treg expansion more efficiently than MSC-EVs pretreated with TGF- $\beta$ or IFN- $\gamma$ only and display higher levels of IDO, IL-10, and IFN- $\gamma$ (Zhang et al., 2018b). Nevertheless, the promoting effect of inflammatory priming was not confirmed by other authors (Kilpinen et al., 2013; Cosenza et al., 2018), who either found a major effect of resting MSC-EVs, or a negligible effect on T cell proliferation of both resting and primed (TNF- $\alpha$ and IFN- $\gamma$ ) MSC-EVs (Kilpinen et al., 2013; Di Trapani et al., 2016; Cosenza et al., 2018).

Altogether, these data give an idea about the complexity of the interactions and effects that can be mediated by MSC$\mathrm{EVs}$ in physiological and reactive conditions, depending on microenvironmental factors, activating stimuli, effector cell subsets and cellular cross-talk. This scenery becomes even more complex when MSC-EVs are administered as cell-free therapeutic approaches in autoimmune or inflammatory conditions.

\section{MSC-EV-Based Immunotherapy}

MSC systemic administration, which must follow Good Manufacturing Practice (GMP) rules, is not associated to 
a significant evidence of cell engraftment even in presence of clinical benefit, due to the entrapment of MSCs in the microvasculature of filter organs, such as lungs (Moll et al., 2016; Salvadori et al., 2019). Other biology aspects can interfere with therapeutic efficacy of MSCs. For instance, the quality and the integrity of MSC preparations depends on the isolation, culture, and cryopreservation methods (Moll et al., 2016; Dufrane, 2017; Mastrolia et al., 2019). Although autologous MSCs would be the best choice for MSC therapy, they showed some limitations: patients' age as well as their genetic traits and medical conditions could reduce the proliferation rate and therapeutic features of MSCs (Pachón-Peña et al., 2016; Dufrane, 2017). Limitations have been also observed in allogeneic MSC transplantation. Indeed, despite MSC have been always considered characterized by a low immunogenic potential, recent studies demonstrated that MSCs may elicit anti-donor immune response (Ankrum et al., 2014; Lohan et al., 2017). Therefore, in order to switch toward a cell-free approach, many groups began to study the immunomodulatory effects of MSC-EVs administered in vivo. One of the first clinical setting in which employing MSCEVs was acute GvHD, the main complication of allogeneic hematopoietic stem cell transplantation (HSCT) (Ferrara et al., 2009; Szyska and Na, 2016; Zeiser and Blazar, 2017). Acute GvHD (aGvHD) occurs within 40 days after HSCT transplantation, as a consequence of interactions between mature donor $\mathrm{T}$ cells and host and donor APCs, mounting a strong immune response that eventually lead to host tissue damage (Tyndall and Dazzi, 2008; Zeiser and Blazar, 2017). On the other hand, chronic GvHD (cGvHD) can arise de novo or from aGvHD and is a more complex disease involving not only mature donor $\mathrm{T}$ cells, but also auto/alloreactive $\mathrm{B}$ cells escaping negative selection (Toubai et al., 2008; Zeiser and Blazar, 2017; Hill et al., 2018). Despite several prophylactic and therapeutic strategies have been developed, the mortality rate of refractory aGvHD is still $70-80 \%$, mostly due to severe secondary infectious complications (Jamil and Mineishi, 2015; Hamilton, 2018).

MSCs initially represented an interesting candidate for cellular therapy to improve HSCT engraftment, prevent graft failure and treat refractory aGvHD. Despite several preclinical and clinical studies showing clinical and survival improvement in MSCtreated patients compared to controls, a significant number of clinical trials failed, especially in adults, probably due to the lack of appropriate knowledge of the mechanisms of action when MSCs are administered in vivo (Elgaz et al., 2019; Cheung et al., 2020). For this reason, several groups started to investigate the effectiveness of MSC-EVs in aGvHD in vivo models and patients. MSC-EVs may prevent aGvHD onset, attenuate symptoms, and prolong animal survival through several mechanisms. For instance, MSC-EVs is capable of reducing $\mathrm{CD} 8^{+} \mathrm{T}$ cell number, leading to the increase of $\mathrm{CD} 4^{+} / \mathrm{CD} 8^{+} \mathrm{T}$ cell ratio; in addition, they block $\mathrm{CD}^{+} \mathrm{T}$ cell migration and activation inside target organs, promote Treg expansion, downregulate IL-2, CCR6, TNF- $\alpha$, and IFN- $\gamma$ expression while increasing IL-10, reduce Th17 cell recruitment while lowering ROR $\gamma \tau$, STAT3, IL-17, IL-21, IL-22 expression (Wang et al., 2016; Fujii et al., 2018; Lai et al., 2018; Zhang et al., 2018a; Dal Collo et al., 2020). Other potential MSC-EV immunomodulatory mechanisms on
T cells involve miR-223 and the adenosine metabolism. miR223, which is highly expressed in EVs from umbilical cord, is capable of inhibiting allogenic $\mathrm{T}$ cell migration and extravasation by targeting ICAM-1, thus leading to a reduction of proinflammatory factors and GvHD symptoms (Liu et al., 2020). Regarding adenosine metabolism, it has been observed in a humanized GvHD mouse model that MSC-EVs can transfer CD73 to CD39 enzyme on the surface of tissue-infiltrating Th1 cells, thus inducing a significant production of adenosine that eventually reduces CD39 expression, enhances apoptosis of adenosine A2A receptor-expressing Th1 cells, and downregulates IFN- $\gamma$ and TNF- $\alpha$ expression, without inducing Tregs (Amarnath et al., 2015). The involvement of adenosine metabolism in $\mathrm{T}$ cell modulation was also confirmed by other groups (Kerkelä et al., 2016; Crain et al., 2018). Interestingly, the anti-GvHD function is restricted to MSC-EVs, as human dermal fibroblastderived EVs are devoid of these effects (Fujii et al., 2018). MSC-EV treatment was also tested in a therapy-refractory GvHD patient, who showed GvHD clinical symptoms improvement and remained stable for several months (Kordelas et al., 2014): MSCEV preparations contained high concentrations of IL-10, TGF- $\beta$, and HLA-G that paralleled with the decrease in the number of both PBMCs releasing IL- $1 \beta$, TNF- $\alpha$, and IFN- $\gamma$ and stimulated NK cells releasing TNF $\alpha$ - or IFN- $\gamma$ (Kordelas et al., 2014).

Unfortunately, not all EV preparations from MSCs are functionally equivalent (Madel et al., 2019). Therefore, it is necessary to characterize the functional activity of MSC-EV preparations and to identify predictive tests that may foresee the clinical benefit. Kordelas et al. (2019) proposed an in vitro assay to monitor the impact of different EV preparations from human donor bone marrow MSCs (BM-MSCs)-MSCs on T cell differentiation and corresponding cytokine production. Recently, a functional in vitro assay was suggested to assess the MSC-EV therapeutic dose (EV-TD) in vivo in a mouse model of aGvHD; EV-TD, associated with the improvement of mouse overall survival, corresponded to 10 -fold the EV immunomodulatory functional unit (EV-IFU), i.e. the lowest concentration in vitro of resting MSC-EV-pool leading to at least threefold increase of Tregs compared to control (Dal Collo et al., 2020). Nevertheless, all these assays need to be validated in a large cohort of patients before being accepted as predictive methods of MSC-EV therapeutic efficacy.

Other clinical studies employing MSC-EVs as treatment of many diseases with inflammatory phenomena are reported on clinicaltrials.gov. According to our search, using the terms "mesenchymal extracellular vesicles" and "stromal extracellular vesicles," only three clinical studies have been registered concerning bronchopulmonary dysplasia (NCT03857841) osteoarthritis (NCT04223622) $)^{2}$, and dystrophic epidermolysis bullosa (NCT04173650) ${ }^{3}$. In particular, NCT03857841 study will employ UNEX-42, a preparation of EVs secreted from human BM-MSCs suspended in phosphate-buffered saline; NCT04223622 study will use the entire secretome or EVs derived

\footnotetext{
${ }^{1}$ https://clinicaltrials.gov/ct2/show/NCT03857841

${ }^{2}$ https://clinicaltrials.gov/ct2/show/study/NCT04223622

${ }^{3}$ https://clinicaltrials.gov/ct2/show/study/NCT04173650
} 
from adipogenic MSCs; and NCT04173650 study will employ AGLE-102, an allogeneic derived EV product derived from normal donor MSCs. However, all studies are currently ongoing and no clear-cut results have been reported so far.

\section{CONCLUSION}

Immunomodulatory capacity of MSCs is associated, at least in part, with the release of EVs. The ability of MSC-EVs to affect immune response, promoting immunotolerance in tissue microenvironment, opens new cues on intercellular communication through soluble factors and makes MSC-EVs a new promising therapeutic strategy for the treatment of many inflammatory disorders. Compared to cell therapy, EV treatment offers a number of advantages in terms of higher distribution in target organs, lower immunogenicity and tumorigenicity as well as easier handling and preparation procedures. Unfortunately, MSC-EVs can have variable biological effects on the same effector cell type depending on different factors, such as the quality of primary cells, MSC source, culture conditions,

\section{REFERENCES}

Adamo, A., Brandi, J., Caligola, S., Delfino, P., Bazzoni, R., Carusone, R., et al. (2019). Extracellular vesicles mediate mesenchymal stromal cell-dependent regulation of B cell PI3K-AKT signaling pathway and actin cytoskeleton. Front. Immunol. 10:446. doi: 10.3389/fimmu.2019.00446

Álvarez, V., Sánchez-Margallo, F. M., Macías-García, B., Gómez-Serrano, M., Jorge, I., Vázquez, J., et al. (2018). The immunomodulatory activity of extracellular vesicles derived from endometrial mesenchymal stem cells on CD4+ T cells is partially mediated by TGFbeta. J. Tissue Eng. Regen. Med. 12, 2088-2098. doi: $10.1002 /$ term. 2743

Amarnath, S., Foley, J. E., Farthing, D. E., Gress, R. E., Laurence, A., Eckhaus, M. A., et al. (2015). Bone marrow-derived mesenchymal stromal cells harness purinergenic signaling to tolerize human Th1 cells in vivo. Stem Cells 33, 1200-1212. doi: 10.1002/stem.1934

Ankrum, J. A., Ong, J. F., and Karp, J. M. (2014). Mesenchymal stem cells: immune evasive, not immune privileged. Nat. Biotechnol. 32, 252-260. doi: 10.1038/nbt. 2816

Ansboro, S., Roelofs, A. J., and De Bari, C. (2017). Mesenchymal stem cells for the management of rheumatoid arthritis: immune modulation, repair or both? Curr. Opin. Rheumatol. 29, 201-207. doi: 10.1097/BOR.000000000000 0370

Bagno, L., Hatzistergos, K. E., Balkan, W., and Hare, J. M. (2018). Mesenchymal stem cell-based therapy for cardiovascular disease: progress and challenges. Mol. Ther. 26, 1610-1623. doi: 10.1016/j.ymthe.2018.05.009

Bai, L., Shao, H., Wang, H., Zhang, Z., Su, C., Dong, L., et al. (2017). Effects of mesenchymal stem cell-derived exosomes on experimental autoimmune uveitis. Sci. Rep. 7:4323. doi: 10.1038/s41598-017-04559-y

Balbi, C., Piccoli, M., Barile, L., Papait, A., Armirotti, A., Principi, E., et al. (2017). First characterization of human amniotic fluid stem cell extracellular vesicles as a powerful paracrine tool endowed with regenerative potential. Stem Cells Transl. Med. 6, 1340-1355. doi: 10.1002/sctm.16-0297

Barrès, C., Blanc, L., Bette-Bobillo, P., André, S., Mamoun, R., Gabius, H. J., et al. (2010). Galectin-5 is bound onto the surface of rat reticulocyte exosomes and modulates vesicle uptake by macrophages. Blood 115, 696-705. doi: 10.1182/ blood-2009-07-231449

Battistelli, M., and Falcieri, E. (2020). Apoptotic bodies: particular extracellular vesicles involved in intercellular communication. Biology 9:21. doi: 10.3390/ biology 9010021

Bier, A., Berenstein, P., Kronfeld, N., Morgoulis, D., Ziv-Av, A., Goldstein, H., et al. (2018). Placenta-derived mesenchymal stromal cells and their exosomes exert preconditioning with inflammatory cytokines, cryopreservation methods, purification and quantification protocols, etc. (Théry et al., 2018). These premises, together with the lack of standardized approaches, specific dosing and defined quality controls for clinical use, require further investigations before transferring EV-based treatments from bench to bedside.

\section{AUTHOR CONTRIBUTIONS}

$\mathrm{RB}$ wrote the manuscript and prepared the figure. PT and IT critically revised the manuscript. MK planned and revised the final version of the manuscript. All authors approved the submitted version of the manuscript.

\section{ACKNOWLEDGMENTS}

We would like to thank the Laboratorio Universitario di Ricerca Medica (L.U.R.M.) of University of Verona for its kindly support to our work.

therapeutic effects in Duchenne muscular dystrophy. Biomaterials 174, 67-78. doi: 10.1016/j.biomaterials.2018.04.055

Blazquez, R., Sanchez-Margallo, F. M., de la Rosa, O., Dalemans, W., Alvarez, V., Tarazona, R., et al. (2014). Immunomodulatory potential of human adipose mesenchymal stem cells derived exosomes on in vitro stimulated T cells. Front. Immunol. 5:556. doi: 10.3389/fimmu.2014.00556

Bouffi, C., Bony, C., Courties, G., Jorgensen, C., and Noël, D. (2010). IL6-dependent PGE2 secretion by mesenchymal stem cells inhibits local inflammation in experimental arthritis. PLoS One 5:e14247. doi: 10.1371/ journal.pone.0014247

Budoni, M., Fierabracci, A., Luciano, R., Petrini, S., Di Ciommo, V., and Muraca, M. (2013). The immunosuppressive effect of mesenchymal stromal cells on B lymphocytes is mediated by membrane vesicles. Cell Transplant. 22, 369-379. doi: 10.3727/096368911X582769b

Burrello, J., Monticone, S., Gai, C., Gomez, Y., Kholia, S., and Camussi, G. (2016). Stem cell-derived extracellular vesicles and immune-modulation. Front. Cell Dev. Biol. 4:83. doi: 10.3389/fcell.2016.00083

Camilleri, E. T., Gustafson, M. P., Dudakovic, A., Riester, S. M., Garces, C. G., Paradise, C. R., et al. (2016). Identification and validation of multiple cell surface markers of clinical-grade adipose-derived mesenchymal stromal cells as novel release criteria for good manufacturing practicecompliant production. Stem Cell Res. Ther. 7:107. doi: 10.1186/s13287-0160370-8

Cao, L., Xu, H., Wang, G., Liu, M., Tian, D., and Yuan, Z. (2019). Extracellular vesicles derived from bone marrow mesenchymal stem cells attenuate dextran sodium sulfate-induced ulcerative colitis by promoting M2 macrophage polarization. Int. Immunopharmacol. 72, 264-274. doi: 10.1016/j.intimp.2019. 04.020

Carreras-Planella, L., Monguió-Tortajada, M., Borràs, F. E., and Franquesa, M. (2019). Immunomodulatory effect of MSC on B cells is independent of secreted extracellular vesicles. Front. Immunol. 10:1288. doi: 10.3389/fimmu.2019.01288

Caruso, S., and Poon, I. K. H. (2018). Apoptotic cell-derived extracellular vesicles: more than just debris. Front. Immunol. 9:1486. doi: 10.3389/fimmu.2018.01486

Caseiro, A. R., Santos Pedrosa, S., Ivanova, G., Vieira Branquinho, M., Almeida, A., Faria, F., et al. (2019). Mesenchymal Stem/ Stromal Cells metabolomic and bioactive factors profiles: a comparative analysis on the umbilical cord and dental pulp derived Stem/ Stromal Cells secretome. PLoS One 14:e0221378. doi: 10.1371/journal.pone.0221378

Chen, Q., Duan, X., Xu, M., Fan, H., Dong, Y., Wu, H., et al. (2020). BMSC-EVs regulate Th17 cell differentiation in UC via H3K27me3. Mol. Immunol. 118, 191-200. doi: 10.1016/j.molimm.2019.12.019 
Chen, W., Huang, Y., Han, J., Yu, L., Li, Y., Lu, Z., et al. (2016). Immunomodulatory effects of mesenchymal stromal cells-derived exosome. Immunol. Res. 64, 831840. doi: 10.1007/s12026-016-8798-6

Cheung, T. S., Bertolino, G. M., Giacomini, C., Bornhäuser, M., Dazzi, F., and Galleu, A. (2020). Mesenchymal stromal cells for graft versus host disease: mechanism-based biomarkers. Front. Immunol. 11:1338. doi: 10.3389/fimmu. 2020.01338

Chinnadurai, R., Copland, I. B., Ng, S., Garcia, M., Prasad, M., Arafat, D., et al. (2015). Mesenchymal stromal cells derived from Crohn's patients deploy indoleamine 2,3-dioxygenase-mediated immune suppression, independent of autophagy. Mol. Ther. 23, 1248-1261. doi: 10.1038/mt.2015.67

Chiossone, L., Dumas, P.-Y., Vienne, M., and Vivier, E. (2018). Natural killer cells and other innate lymphoid cells in cancer. Nat. Rev. Immunol. 18, 671-688. doi: 10.1038/s41577-018-0061-z

Chivet, M., Javalet, C., Laulagnier, K., Blot, B., Hemming, F. J., and Sadoul, R. (2014). Exosomes secreted by cortical neurons upon glutamatergic synapse activation specifically interact with neurons. J. Extracell. Vesicles 3:24722. doi: 10.3402/jev.v3.24722

Cho, J., D’Antuono, M., Glicksman, M., Wang, J., and Jonklaas, J. (2018). A review of clinical trials: mesenchymal stem cell transplant therapy in type 1 and type 2 diabetes mellitus. Am. J. Stem Cells 7, 82-93.

Cho, K.-S., Kang, S. A., Kim, S.-D., Mun, S.-J., Yu, H. S., and Roh, H.-J. (2019). Dendritic cells and M2 macrophage play an important role in suppression of Th2-mediated inflammation by adipose stem cells-derived extracellular vesicles. Stem Cell Res. 39:101500. doi: 10.1016/j.scr.2019.101500

Christianson, H. C., Svensson, K. J., van Kuppevelt, T. H., Li, J. P., and Belting, M. (2013). Cancer cell exosomes depend on cell-surface heparan sulfate proteoglycans for their internalization and functional activity. Proc. Natl. Acad. Sci. U.S.A. 110, 17380-17385. doi: 10.1073/pnas.1304266110

Cocucci, E., and Meldolesi, J. (2015). Ectosomes and exosomes: shedding the confusion between extracellular vesicles. Trends Cell Biol. 25, 364-372. doi: 10.1016/j.tcb.2015.01.004

Collin, M., McGovern, N., and Haniffa, M. (2013). Human dendritic cell subsets. Immunology 140, 22-30. doi: 10.1111/imm.12117

Conforti, A., Scarsella, M., Starc, N., Giorda, E., Biagini, S., Proia, A., et al. (2014). Microvescicles derived from mesenchymal stromal cells are not as effective as their cellular counterpart in the ability to modulate immune responses in vitro. Stem Cells Dev. 23, 2591-2599. doi: 10.1089/scd.2014.0091

Cosenza, S., Ruiz, M., Toupet, K., Jorgensen, C., and Noël, D. (2017). Mesenchymal stem cells derived exosomes and microparticles protect cartilage and bone from degradation in osteoarthritis. Sci. Rep. 7:16214. doi: 10.1038/s41598-01715376-8

Cosenza, S., Toupet, K., Maumus, M., Luz-Crawford, P., Blanc-Brude, O., Jorgensen, C., et al. (2018). Mesenchymal stem cells-derived exosomes are more immunosuppressive than microparticles in inflammatory arthritis. Theranostics 8, 1399-1410. doi: 10.7150/thno.21072

Costa Verdera, H., Gitz-Francois, J. J., Schiffelers, R. M., and Vader, P. (2017). Cellular uptake of extracellular vesicles is mediated by clathrin-independent endocytosis and macropinocytosis. J. Control. Release 266, 100-108. doi: 10. 1016/j.jconrel.2017.09.019

Crain, S. K., Robinson, S. R., Thane, K. E., Davis, A. M., Meola, D. M., Barton, B. A., et al. (2018). Extracellular vesicles from wharton's jelly mesenchymal stem cells suppress CD4 expressing T cells through transforming growth factor beta and adenosine signaling in a canine model. Stem Cells Dev. 28, 212-226. doi: 10.1089/scd.2018.0097

Cruz, F. F., Borg, Z. D., Goodwin, M., Sokocevic, D., Wagner, D. E., Coffey, A., et al. (2015). Systemic administration of human bone marrow-derived mesenchymal stromal cell extracellular vesicles ameliorates Aspergillus Hyphal extract-induced allergic airway inflammation in immunocompetent mice. Stem Cells Transl. Med. 4, 1302-1316. doi: 10.5966/sctm.2014-0280

Dabrowska, S., Andrzejewska, A., Strzemecki, D., Muraca, M., Janowski, M., and Lukomska, B. (2019). Human bone marrow mesenchymal stem cell-derived extracellular vesicles attenuate neuroinflammation evoked by focal brain injury in rats. J. Neuroinflammation 16:216. doi: 10.1186/s12974-019-1602-5

Dal Collo, G., Adamo, A., Gatti, A., Tamellini, E., Bazzoni, R., Takam Kamga, P., et al. (2020). Functional dosing of mesenchymal stromal cell-derived extracellular vesicles for the prevention of acute graft-versus-host-disease. Stem Cells 38, 698-711. doi: 10.1002/stem.3160 de Castro, L. L., Xisto, D. G., Kitoko, J. Z., Cruz, F. F., Olsen, P. C., Redondo, P. A. G., et al. (2017). Human adipose tissue mesenchymal stromal cells and their extracellular vesicles act differentially on lung mechanics and inflammation in experimental allergic asthma. Stem Cell Res. Ther. 8:151. doi: 10.1186/s13287-017-0600-8

de Mayo, T., Conget, P., Becerra-Bayona, S., Sossa, C. L., Galvis, V., and ArangoRodríguez, M. L. (2017). The role of bone marrow mesenchymal stromal cell derivatives in skin wound healing in diabetic mice. PLoS One 12:e177533. doi: 10.1371/journal.pone.0177533

Deatherage, B. L., and Cookson, B. T. (2012). Membrane vesicle release in bacteria, eukaryotes, and archaea: a conserved yet underappreciated aspect of microbial life. Infect. Immun. 80, 1948-1957. doi: 10.1128/IAI.06014-11

Del Fattore, A., Luciano, R., Pascucci, L., Goffredo, B. M., Giorda, E., Scapaticci, M., et al. (2015). Immunoregulatory effects of mesenchymal stem cell-derived extracellular vesicles on T lymphocytes. Cell Transplant. 24, 2615-2627. doi: $10.3727 / 096368915 X 687543$

Deng, S., Zhou, X., Ge, Z., Song, Y., Wang, H., Liu, X., et al. (2019). Exosomes from adipose-derived mesenchymal stem cells ameliorate cardiac damage after myocardial infarction by activating S1P/SK1/S1PR1 signaling and promoting macrophage M2 polarization. Int. J. Biochem. Cell Biol. 114:105564. doi: 10. 1016/j.biocel.2019.105564

Di Trapani, M., Bassi, G., Midolo, M., Gatti, A., Kamga, P. T., Cassaro, A., et al. (2016). Differential and transferable modulatory effects of mesenchymal stromal cell-derived extracellular vesicles on T, B and NK cell functions. Sci. Rep. 6:24120. doi: 10.1038/srep24120

Dominici, M., Le Blanc, K., Mueller, I., Slaper-Cortenbach, I., Marini, F., Krause, D., et al. (2006). Minimal criteria for defining multipotent mesenchymal stromal cells. The International Society for Cellular Therapy position statement. Cytotherapy 8, 315-317. doi: 10.1080/14653240600855905

Du, W. J., Reppel, L., Leger, L., Schenowitz, C., Huselstein, C., Bensoussan, D., et al. (2016). Mesenchymal stem cells derived from human bone marrow and adipose tissue maintain their immunosuppressive properties after chondrogenic differentiation: role of HLA-G. Stem Cells Dev. 25, 1454-1469. doi: $10.1089 /$ scd.2016.0022

Du, Y. M., Zhuansun, Y. X., Chen, R., Lin, L., Lin, Y., and Li, J. G. (2018). Mesenchymal stem cell exosomes promote immunosuppression of regulatory T cells in asthma. Exp. Cell Res. 363, 114-120. doi: 10.1016/j.yexcr.2017.12.021

Duffy, M. M., Ritter, T., Ceredig, R., and Griffin, M. D. (2011). Mesenchymal stem cell effects on T-cell effector pathways. Stem Cell Res. Ther. 2:34. doi: $10.1186 /$ scrt75

Dufrane, D. (2017). Impact of age on human adipose stem cells for bone tissue engineering. Cell Transplant. 26, 1496-1504. doi: 10.1177/0963689717721203

Elgaz, S., Kuçi, Z., Kuçi, S., Bönig, H., and Bader, P. (2019). Clinical use of mesenchymal stromal cells in the treatment of acute graft-versus-host disease. Transfus. Med. Hemother. 46, 27-34. doi: 10.1159/000496809

Fan, L., Hu, C., Chen, J., Cen, P., Wang, J., and Li, L. (2016). Interaction between mesenchymal stem cells and B-cells. Int. J. Mol. Sci. 17:650. doi: 10.3390/ ijms 17050650

Fan, Y., Herr, F., Vernochet, A., Mennesson, B., Oberlin, E., and Durrbach, A. (2018). Human fetal liver mesenchymal stem cell-derived exosomes impair natural killer cell function. Stem Cells Dev. 28, 44-55. doi: 10.1089/scd.2018. 0015

Farinazzo, A., Angiari, S., Turano, E., Bistaffa, E., Dusi, S., Ruggieri, S., et al. (2018). Nanovesicles from adipose-derived mesenchymal stem cells inhibit $\mathrm{T}$ lymphocyte trafficking and ameliorate chronic experimental autoimmune encephalomyelitis. Sci. Rep. 8:7473. doi: 10.1038/s41598-018-25 $676-2$

Favaro, E., Carpanetto, A., Caorsi, C., Giovarelli, M., Angelini, C., Cavallo-Perin, P., et al. (2016). Human mesenchymal stem cells and derived extracellular vesicles induce regulatory dendritic cells in type 1 diabetic patients. Diabetologia 59, 325-333. doi: 10.1007/s00125-015-3808-0

Favaro, E., Carpanetto, A., Lamorte, S., Fusco, A., Caorsi, C., Deregibus, M. C., et al. (2014). Human mesenchymal stem cell-derived microvesicles modulate $\mathrm{T}$ cell response to islet antigen glutamic acid decarboxylase in patients with type 1 diabetes. Diabetologia 57, 1664-1673. doi: 10.1007/s00125-014-3262-4

Feng, D., Zhao, W. L., Ye, Y. Y., Bai, X. C., Liu, R. Q., Chang, L. F., et al. (2010). Cellular internalization of exosomes occurs through phagocytosis. Traffic 11, 675-687. doi: 10.1111/j.1600-0854.2010.01041.x 
Ferrara, J. L., Levine, J. E., Reddy, P., and Holler, E. (2009). Graft-versus-host disease. Lancet 373, 1550-1561. doi: 10.1016/s0140-6736(09)60237-3

Fierabracci, A., Del Fattore, A., Luciano, R., Muraca, M., Teti, A., and Muraca, M. (2015). Recent advances in mesenchymal stem cell immunomodulation: the role of microvesicles. Cell Transplant. 24, 133-149. doi: 10.3727/ 096368913 X675728

Fiore, E., Domínguez, L. M., Bayo, J., Malvicini, M., Atorrasagasti, C., Rodriguez, M., et al. (2020). Human umbilical cord perivascular cells-derived extracellular vesicles mediate the transfer of IGF-I to the liver and ameliorate hepatic fibrogenesis in mice. Gene Ther. 27, 62-73. doi: 10.1038/s41434-019$0102-7$

Fitzner, D., Schnaars, M., van Rossum, D., Krishnamoorthy, G., Dibaj, P., Bakhti, M., et al. (2011). Selective transfer of exosomes from oligodendrocytes to microglia by macropinocytosis. J. Cell Sci. 124, 447-458. doi: 10.1242/jcs. 074088

Forbes, G. M. (2017). Mesenchymal stromal cell therapy in Crohn's disease. Dig. Dis. 35, 115-122. doi: 10.1159/000449091

Friedenstein, A. J., Piatetzky-Shapiro, I. I., and Petrakova, K. V. (1966). Osteogenesis in transplants of bone marrow cells. J. Embryol. Exp. Morphol. $16,381-390$.

Fujii, S., Miura, Y., Fujishiro, A., Shindo, T., Shimazu, Y., Hirai, H., et al. (2018). Graft-versus-host disease amelioration by human bone marrow mesenchymal stromal/stem cell-derived extracellular vesicles is associated with peripheral preservation of naive T cell populations. Stem Cells 36, 434-445. doi: 10.1002/ stem. 2759

Fukutake, M., Ochiai, D., Masuda, H., Abe, Y., Sato, Y., Otani, T., et al. (2019). Human amniotic fluid stem cells have a unique potential to accelerate cutaneous wound healing with reduced fibrotic scarring like a fetus. Hum. Cell 32, 51-63. doi: 10.1007/s13577-018-0222-1

Galleu, A., Riffo-Vasquez, Y., Trento, C., Lomas, C., Dolcetti, L., Cheung, T. S., et al. (2017). Apoptosis in mesenchymal stromal cells induces in vivo recipientmediated immunomodulation. Sci. Transl. Med. 9:eaam7828. doi: 10.1126/ scitranslmed.aam7828

Gao, F., Chiu, S. M., Motan, D. A., Zhang, Z., Chen, L., Ji, H. L., et al. (2016). Mesenchymal stem cells and immunomodulation: current status and future prospects. Cell Death Dis. 7:e2062. doi: 10.1038/cddis.2015.327

Gill, S., Catchpole, R., and Forterre, P. (2019). Extracellular membrane vesicles in the three domains of life and beyond. FEMS Microbiol. Rev. 43, 273-303. doi: 10.1093/femsre/fuy042

Gould, S. J., and Raposo, G. (2013). As we wait: coping with an imperfect nomenclature for extracellular vesicles. J. Extracell. Vesicles 2:20389. doi: 10. 3402/jev.v2i0.20389

Gouveia de Andrade, A. V., Bertolino, G., Riewaldt, J., Bieback, K., Karbanová, J., Odendahl, M., et al. (2015). Extracellular vesicles secreted by bone marrow- and adipose tissue-derived mesenchymal stromal cells fail to suppress lymphocyte proliferation. Stem Cells Dev. 24, 1374-1376. doi: 10.1089/scd.2014.0563

Grange, C., Tapparo, M., Tritta, S., Deregibus, M. C., Battaglia, A., Gontero, P., et al. (2015). Role of HLA-G and extracellular vesicles in renal cancer stem cell-induced inhibition of dendritic cell differentiation. BMC Cancer 15:1009. doi: $10.1186 / \mathrm{s} 12885-015-2025-\mathrm{z}$

Guo, L., Lai, P., Wang, Y., Huang, T., Chen, X., Luo, C., et al. (2019). Extracellular vesicles from mesenchymal stem cells prevent contact hypersensitivity through the suppression of Tc1 and Th1 cells and expansion of regulatory T cells. Int. Immunopharmacol. 74:105663. doi: 10.1016/j.intimp.2019.05.048

Haddad, R., and Saldanha-Araujo, F. (2014). Mechanisms of T-cell immunosuppression by mesenchymal stromal cells: what do we know so far? Biomed Res. Int. 2014:216806. doi: 10.1155/2014/216806

Hai, B., Shigemoto-Kuroda, T., Zhao, Q., Lee, R. H., and Liu, F. (2018). Inhibitory Effects of iPSC-MSCs and their extracellular vesicles on the onset of sialadenitis in a mouse model of Sjögren's syndrome. Stem Cells Int. 2018:2092315. doi: $10.1155 / 2018 / 2092315$

Hall, S. R., Tsoyi, K., Ith, B., Padera, R. F. Jr., Lederer, J. A., Wang Z., et al. (2013). Mesenchymal stromal cells improve survival during sepsis in the absence of heme oxygenase-1: the importance of neutrophils. Stem Cells 31, 397-407. doi: $10.1002 /$ stem. 1270

Hamilton, B. K. (2018). Current approaches to prevent and treat GVHD after allogeneic stem cell transplantation. Hematology Am. Soc. Hematol. Educ. Program 2018, 228-235. doi: 10.1182/asheducation-2018.1.228
Hao, S., Bai, O., Li, F., Yuan, J., Laferte, S., and Xiang, J. (2007). Mature dendritic cells pulsed with exosomes stimulate efficient cytotoxic T-lymphocyte responses and antitumour immunity. Immunology 120, 90-102. doi: 10.1111/j.1365-2567. 2006.02483.x

Harting, M. T., Srivastava, A. K., Zhaorigetu, S., Bair, H., Prabhakara, K. S., Toledano Furman, N. E., et al. (2018). Inflammation-stimulated mesenchymal stromal cell-derived extracellular vesicles attenuate inflammation. Stem Cells 36, 79-90. doi: $10.1002 /$ stem. 2730

He, X., Dong, Z., Cao, Y., Wang, H., Liu, S., Liao, L., et al. (2019). MSC-derived exosome promotes M2 polarization and enhances cutaneous wound healing. Stem Cells Int. 2019:7132708. doi: 10.1155/2019/7132708

Henao Agudelo, J. S., Braga, T. T., Amano, M. T., Cenedeze, M. A., Cavinato, R. A., Peixoto-Santos, A. R., et al. (2017). Mesenchymal stromal cell-derived microvesicles regulate an internal pro-inflammatory program in activated macrophages. Front. Immunol. 8:881. doi: 10.3389/fimmu.2017.00881

Hill, L., Alousi, A., Kebriaei, P., Mehta, R., Rezvani, K., and Shpall, E. (2018). New and emerging therapies for acute and chronic graft versus host disease. Ther. Adv. Hematol. 9, 21-46. doi: 10.1177/2040620717741860

Horibe, S., Tanahashi, T., Kawauchi, S., Murakami, Y., and Rikitake, Y. (2018). Mechanism of recipient cell-dependent differences in exosome uptake. BMC Cancer 18:47. doi: 10.1186/s12885-017-3958-1

Hyvärinen, K., Holopainen, M., Skirdenko, V., Ruhanen, H., Lehenkari, P., Korhonen, M., et al. (2018). Mesenchymal stromal cells and their extracellular vesicles enhance the anti-inflammatory phenotype of regulatory macrophages by downregulating the production of interleukin (IL)-23 and IL-22. Front. Immunol. 9:771. doi: 10.3389/fimmu.2018.00771

Jamil, M. O., and Mineishi, S. (2015). State-of-the-art acute and chronic GVHD treatment. Int. J. Hematol. 101, 452-466. doi: 10.1007/s12185-015-1785-1

Ji, L., Bao, L., Gu, Z., Zhou, Q., Liang, Y., Zheng, Y., et al. (2019). Comparison of immunomodulatory properties of exosomes derived from bone marrow mesenchymal stem cells and dental pulp stem cells. Immunol. Res. 67, 432-442. doi: 10.1007/s12026-019-09088-6

Jiang, L., Zhang, S., Hu, H., Yang, J., Wang, X., Ma, Y., et al. (2019). Exosomes derived from human umbilical cord mesenchymal stem cells alleviate acute liver failure by reducing the activity of the NLRP3 inflammasome in macrophages. Biochem. Biophys. Res. Commun. 508, 735-741. doi: 10.1016/j.bbrc.2018.11.189

Kang, H., Lee, M.-J., Park, S. J., and Lee, M.-S. (2018). Lipopolysaccharidepreconditioned periodontal ligament stem cells induce M1 polarization of macrophages through extracellular vesicles. Int. J. Mol. Sci. 19:3843. doi: 10. 3390/ijms 19123843

Kerkelä, E., Laitinen, A., Räbinä, J., Valkonen, S., Takatalo, M., Larjo, A., et al. (2016). Adenosinergic immunosuppression by human mesenchymal stromal cells requires co-operation with T cells. Stem Cells 34, 781-790. doi: 10.1002/ stem.2280

Khare, D., Or, R., Resnick, I., Barkatz, C., Almogi-Hazan, O., and Avni, B. (2018). Mesenchymal stromal cell-derived exosomes affect mRNA expression and function of B-Lymphocytes. Front. Immunol. 9:3053. doi: 10.3389/fimmu.2018. 03053

Kilpinen, L., Impola, U., Sankkila, L., Ritamo, I., Aatonen, M., Kilpinen, S., et al. (2013). Extracellular membrane vesicles from umbilical cord blood-derived MSC protect against ischemic acute kidney injury, a feature that is lost after inflammatory conditioning. J. Extracell. Vesicles 2:21927. doi: 10.3402/jev.v2i0. 21927

Ko, S.-F., Yip, H.-K., Zhen, Y.-Y., Lee, C.-C., Lee, C.-C., Huang, C.-C., et al. (2015). Adipose-derived mesenchymal stem cell exosomes suppress hepatocellular carcinoma growth in a rat model: apparent diffusion coefficient, Natural Killer T-Cell Responses, and Histopathological Features. Stem Cells Int. 2015:853506. doi: $10.1155 / 2015 / 853506$

Koch, M., Lemke, A., and Lange, C. (2015). Extracellular vesicles from MSC modulate the immune response to renal allografts in a MHC disparate rat model. Stem Cells Int. 2015:486141. doi: 10.1155/2015/486141

Kordelas, L., Rebmann, V., Ludwig, A. K., Radtke, S., Ruesing, J., Doeppner, T. R., et al. (2014). MSC-derived exosomes: a novel tool to treat therapy-refractory graft-versus-host disease. Leukemia 28, 970-973. doi: 10.1038/leu.2014.41

Kordelas, L., Schwich, E., Dittrich, R., Horn, P. A., Beelen, D. W., Borger, $\mathrm{V}$., et al. (2019). Individual immune-modulatory capabilities of MSC-derived extracellular vesicle (EV) preparations and recipient-dependent responsiveness. Int. J. Mol. Sci. 20:1642. doi: 10.3390/ijms20071642 
Kraitchman, D. L., Tatsumi, M., Gilson, W. D., Ishimori, T., Kedziorek, D., Walczak, P., et al. (2005). Dynamic imaging of allogeneic mesenchymal stem cells trafficking to myocardial infarction. Circulation 112, 1451-1461. doi: 10. 1161/CIRCULATIONAHA.105.537480

Krampera, M. (2011). Mesenchymal stromal cell 'licensing': a multistep process. Leukemia 25, 1408-1414. doi: 10.1038/leu.2011.108

Kumar, B. V., Connors, T. J., and Farber, D. L. (2018). Human T cell development, localization, and function throughout life. Immunity 48, 202-213. doi: 10.1016/ j.immuni.2018.01.007

Lai, P., Chen, X., Guo, L., Wang, Y., Liu, X., Liu, Y., et al. (2018). A potent immunomodulatory role of exosomes derived from mesenchymal stromal cells in preventing cGVHD. J. Hematol. Oncol. 11:135. doi: 10.1186/s13045-0180680-7

Lai, R. C., Tan, S. S., Yeo, R. W., Choo, A. B., Reiner, A. T., Su, Y., et al. (2016). MSC secretes at least $3 \mathrm{EV}$ types each with a unique permutation of membrane lipid, protein and RNA. J. Extracell. Vesicles 5:29828. doi: 10.3402/jev.v5.29828

Lankford, K. L., Arroyo, E. J., Nazimek, K., Bryniarski, K., Askenase, P. W., and Kocsis, J. D. (2018). Intravenously delivered mesenchymal stem cell-derived exosomes target M2-type macrophages in the injured spinal cord. PLoS One 13:e0190358. doi: 10.1371/journal.pone.0190358

Le Blanc, K., Frassoni, F., Ball, L., Locatelli, F., Roelofs, H., Lewis, I., et al. (2008). Mesenchymal stem cells for treatment of steroid-resistant, severe, acute graftversus-host disease: a phase II study. Lancet 371, 1579-1586. doi: 10.1016/ S0140-6736(08)60690-X

Lee, S. S., Won, J. H., Lim, G. J., Han, J., Lee, J. Y., Cho, K. O., et al. (2019). A novel population of extracellular vesicles smaller than exosomes promotes cell proliferation. Cell Commun. Signal. 17:95. doi: 10.1186/s12964-0190401-z

Li, J., Xue, H., Li, T., Chu, X., Xin, D., Xiong, Y., et al. (2019). Exosomes derived from mesenchymal stem cells attenuate the progression of atherosclerosis in ApoE-/- mice via miR-let7 mediated infiltration and polarization of M2 macrophage. Biochem. Biophys. Res. Commun. 510, 565-572. doi: 10.1016/j. bbrc.2019.02.005

Li, X., Liu, L., Yang, J., Yu, Y., Chai, J., Wang, L., et al. (2016). Exosome derived from human umbilical cord mesenchymal stem cell mediates MiR-181c attenuating burn-induced excessive inflammation. EBioMedicine 8, 72-82. doi: 10.1016/j. ebiom.2016.04.030

Liu, F., Qiu, H., Xue, M., Zhang, S., Zhang, X., Xu, J., et al. (2019). MSCsecreted TGF- $\beta$ regulates lipopolysaccharide-stimulated macrophage M2-like polarization via the Akt/FoxO1 pathway. Stem Cell Res. Ther. 10:345. doi: 10. 1186/s13287-019-1447-y

Liu, W., Zhou, N., Wang, P., Liu, Y., Zhang, W., and Li, X. (2020). MiR-223 Derived from Mesenchymal Stem Cell Exosomes Alleviates Acute Graft-VersusHost Disease. PREPRINT (Version 1). Available online at: https://doi.org/10. 21203/rs.3.rs-28347/v1 (accessed May 19, 2020).

Liu, Y., Lou, G., Li, A., Zhang, T., Qi, J., Ye, D., et al. (2018). AMSCderived exosomes alleviate lipopolysaccharide/d-galactosamine-induced acute liver failure by miR-17-mediated reduction of TXNIP/NLRP3 inflammasome activation in macrophages. EBioMedicine 36, 140-150. doi: 10.1016/j.ebiom. 2018.08.054

Lo Sicco, C., Reverberi, D., Balbi, C., Ulivi, V., Principi, E., Pascucci, L., et al. (2017). Mesenchymal stem cell-derived extracellular vesicles as mediators of anti-inflammatory effects: endorsement of macrophage polarization. Stem Cells Transl. Med. 6, 1018-1028. doi: 10.1002/sctm.16-0363

Lohan, P., Treacy, O., Griffin, M. D., Ritter, T., and Ryan, A. E. (2017). Antidonor immune responses elicited by allogeneic mesenchymal stem cells and their extracellular vesicles: Are we still learning? Front. Immunol. 8:1626. doi: 10.3389/fimmu.2017.01626

Lu, Z., Chang, W., Meng, S., Xu, X., Xie, J., Guo, F., et al. (2019). Mesenchymal stem cells induce dendritic cell immune tolerance via paracrine hepatocyte growth factor to alleviate acute lung injury. Stem Cell Res. Ther. 10:372. doi: 10.1186/s13287-019-1488-2

Ma, D., Xu, K., Zhang, G., Liu, Y., Gao, J., Tian, M., et al. (2019). Immunomodulatory effect of human umbilical cord mesenchymal stem cells on T lymphocytes in rheumatoid arthritis. Int. Immunopharmacol. 74:105687. doi: 10.1016/j.intimp.2019.105687

Madel, R., Börger, V., Bremer, M., Horn, P., Baba, H. A., Brandau, S., et al. (2019). MSC-EVs protect mice from graft-versus-host disease pathology in a preparation dependent manner. Cytotherapy 21(5, Suppl.):S57. doi: 10.1016/j. jcyt.2019.03.429

Marinaro, F., Gómez-Serrano, M., Jorge, I., Silla-Castro, J. C., Vázquez, J., Sánchez-Margallo, F. M., et al. (2019). Unraveling the molecular signature of extracellular vesicles from endometrial-derived mesenchymal stem cells: potential modulatory effects and therapeutic applications. Front. Bioeng. Biotechnol. 7:431. doi: 10.3389/fbioe.2019.00431

Marquez-Curtis, L. A., Janowska-Wieczorek, A., McGann, L. E., and Elliott, J. A. W. (2015). Mesenchymal stromal cells derived from various tissues: biological, clinical and cryopreservation aspects. Cryobiology 71, 181-197. doi: 10.1016/ j.cryobiol.2015.07.003

Martin, R. K., Brooks, K. B., Henningsson, F., Heyman, B., and Conrad, D. H. (2014). Antigen transfer from exosomes to dendritic cells as an explanation for the immune enhancement seen by IgE immune complexes. PLoS One 9:e110609. doi: 10.1371/journal.pone.0110609

Mastrolia, I., Foppiani, E. M., Murgia, A., Candini, O., Samarelli, A. V., Grisendi, G., et al. (2019). Challenges in clinical development of mesenchymal stromal/stem cells: concise review. Stem Cells Transl. Med. 8, 1135-1148. doi: 10.1002/sctm.19-0044

Matsushita, T. (2019). Regulatory and effector B cells: Friends or foes? J. Dermatol. Sci. 93, 2-7. doi: 10.1016/j.jdermsci.2018.11.008

Mokarizadeh, A., Delirezh, N., Morshedi, A., Mosayebi, G., Farshid, A. A., and Mardani, K. (2012). Microvesicles derived from mesenchymal stem cells: potent organelles for induction of tolerogenic signaling. Immunol. Lett. 147, 47-54. doi: 10.1016/j.imlet.2012.06.001

Moll, G., Geißler, S., Catar, R., Ignatowicz, L., Hoogduijn, M. J., Strunk, D., et al. (2016). Cryopreserved or fresh mesenchymal stromal cells: Only a matter of taste or key to unleash the full clinical potential of MSC therapy? Adv. Exp. Med. Biol. 951, 77-98. doi: 10.1007/978-3-319-45457-3_7

Monguió-Tortajada, M., Roura, S., Gálvez-Montón, C., Pujal, J. M., Aran, G., Sanjurjo, L., et al. (2017). Nanosized UCMSC-derived extracellular vesicles but not conditioned medium exclusively inhibit the inflammatory response of stimulated T cells: implications for nanomedicine. Theranostics 7, 270-284. doi: 10.7150/thno.16154

Montecalvo, A., Larregina, A. T., Shufesky, W. J., Stolz, D. B., Sullivan, M. L. G., Karlsson, J. M., et al. (2012). Mechanism of transfer of functional microRNAs between mouse dendritic cells via exosomes. Blood 119, 756-766. doi: 10.1182/ blood-2011-02-338004

Morelli, A. E., Larregina, A. T., Shufesky, W. J., Sullivan, M. L. G., Stolz, D. B., Papworth, G. D., et al. (2004). Endocytosis, intracellular sorting, and processing of exosomes by dendritic cells. Blood 104, 3257-3266. doi: 10.1182/blood-200403-0824

Moretta, A., Marcenaro, E., Parolini, S., Ferlazzo, G., and Moretta, L. (2008). NK cells at the interface between innate and adaptive immunity. Cell Death Differ. 15, 226-233. doi: 10.1038/sj.cdd.4402170

Morrison, T. J., Jackson, M. V., Cunningham, E. K., Kissenpfennig, A., McAuley, D. F., O’Kane, C. M., et al. (2017). Mesenchymal stromal cells modulate macrophages in clinically relevant lung injury models by extracellular vesicle mitochondrial transfer. Am. J. Respir. Crit. Care Med. 196, 1275-1286. doi: 10.1164/rccm.201701-0170OC

Mou, S., Zhou, M., Li, Y., Wang, J., Yuan, Q., Xiao, P., et al. (2019). Extracellular vesicles from human adipose-derived stem cells for the improvement of angiogenesis and fat-grafting application. Plast. Reconstr. Surg. 144, 869-880. doi: $10.1097 /$ prs.0000000000006046

Nawaz, M., and Fatima, F. (2017). Extracellular vesicles, tunneling nanotubes, and cellular interplay: synergies and missing links. Front. Mol. Biosci. 4:50. doi: 10.3389/fmolb.2017.00050

Németh, K., Leelahavanichkul, A., Yuen, P. S. T., Mayer, B., Parmelee, A., Doi, K., et al. (2009). Bone marrow stromal cells attenuate sepsis via prostaglandin $\mathrm{E}(2)$ dependent reprogramming of host macrophages to increase their interleukin-10 production. Nat. Med. 15, 42-49. doi: 10.1038/nm.1905

Nguyen, D. C., Lewis, H. C., Joyner, C., Warren, V., Xiao, H., Kissick, H. T., et al. (2018). Extracellular vesicles from bone marrow-derived mesenchymal stromal cells support ex vivo survival of human antibody secreting cells. J. Extracell. Vesicles 7:1463778. doi: 10.1080/20013078.2018.146 3778

Nojehdehi, S., Soudi, S., Hesampour, A., Rasouli, S., Soleimani, M., and Hashemi, S. M. (2018). Immunomodulatory effects of mesenchymal stem cell-derived 
exosomes on experimental type-1 autoimmune diabetes. J. Cell. Biochem. 119:9433. doi: $10.1002 /$ jcb. 27260

Pachón-Peña, G., Serena, C., Ejarque, M., Petriz, J., Duran, X., Oliva-Olivera, W., et al. (2016). Obesity determines the immunophenotypic profile and functional characteristics of human mesenchymal stem cells from adipose tissue. Stem Cells Transl. Med. 5, 464-475. doi: 10.5966/sctm.2015-0161

Patente, T. A., Pinho, M. P., Oliveira, A. A., Evangelista, G. C. M., Bergami-Santos, P. C., and Barbuto, J. A. M. (2019). Human dendritic cells: their heterogeneity and clinical application potential in cancer immunotherapy. Front. Immunol. 9:3176. doi: 10.3389/fimmu.2018.03176

Petri, R. M., Hackel, A., Hahnel, K., Dumitru, C. A., Bruderek, K., Flohe, S. B., et al. (2017). Activated tissue-resident mesenchymal stromal cells regulate natural killer cell immune and tissue-regenerative function. Stem Cell Rep. 9, 985-998. doi: 10.1016/j.stemcr.2017.06.020

Phinney, D. G., Di Giuseppe, M., Njah, J., Sala, E., Shiva, S., St Croix, C. M., et al. (2015). Mesenchymal stem cells use extracellular vesicles to outsource mitophagy and shuttle microRNAs. Nat. Commun. 6:8472. doi: 10.1038/ ncomms 9472

Pittenger, M. F., Discher, D. E., Péault, B. M., Phinney, D. G., Hare, J. M., and Caplan, A. I. (2019). Mesenchymal stem cell perspective: cell biology to clinical progress. NPJ Regen. Med. 4:22. doi: 10.1038/s41536-0190083-6

Pokrywczynska, M., Rasmus, M., Jundzill, A., Balcerczyk, D., Adamowicz, J., Warda, K., et al. (2019). Mesenchymal stromal cells modulate the molecular pattern of healing process in tissue-engineered urinary bladder: the microarray data. Stem Cell Res. Ther. 10:176. doi: 10.1186/s13287-0191266-1

Prada, I., Gabrielli, M., Turola, E., Iorio, A., D’Arrigo, G., Parolisi, R., et al. (2018). Glia-to-neuron transfer of miRNAs via extracellular vesicles: a new mechanism underlying inflammation-induced synaptic alterations. Acta Neuropathol. 135, 529-550. doi: 10.1007/s00401-017-1803-x

Rahman, M. J., Regn, D., Bashratyan, R., and Dai, Y. D. (2014). Exosomes released by islet-derived mesenchymal stem cells trigger autoimmune responses in NOD mice. Diabetes 63, 1008-1020. doi: 10.2337/db13-0859

Rai, A. K., and Johnson, P. J. (2019). Trichomonas vaginalis extracellular vesicles are internalized by host cells using proteoglycans and caveolin-dependent endocytosis. Proc. Natl. Acad. Sci. U.S.A. 116, 21354-21360. doi: 10.1073/pnas. 1912356116

Rani, S., Ryan, A. E., Griffin, M. D., and Ritter, T. (2015). Mesenchymal stem cellderived extracellular vesicles: toward cell-free therapeutic applications. Mol. Ther. 23, 812-823. doi: 10.1038/mt.2015.44

Raposo, G., Nijman, H. W., Stoorvogel, W., Liejendekker, R., Harding, C. V., Melief, C. J., et al. (1996). B lymphocytes secrete antigen-presenting vesicles. J. Exp. Med. 183, 1161-1172. doi: 10.1084/jem.183.3.1161

Ratajczak, J., Wysoczynski, M., Hayek, F., Janowska-Wieczorek, A., and Ratajczak, M. Z. (2006). Membrane-derived microvesicles: important and underappreciated mediators of cell-to-cell communication. Leukemia 20, 14871495. doi: 10.1038/sj.leu.2404296

Reis, M., Mavin, E., Nicholson, L., Green, K., Dickinson, A. M., and Wang, X. N. (2018). Mesenchymal stromal cell-derived extracellular vesicles attenuate dendritic cell maturation and function. Front. Immunol. 9:2538. doi: 10.3389/ fimmu.2018.02538

Riekstina, U., Muceniece, R., Cakstina, I., Muiznieks, I., and Ancans, J. (2008). Characterization of human skin-derived mesenchymal stem cell proliferation rate in different growth conditions. Cytotechnology 58, 153-162. doi: 10.1007/ s10616-009-9183-2

Romani, R., Pirisinu, I., Calvitti, M., Pallotta, M. T., Gargaro, M., Bistoni, G., et al. (2015). Stem cells from human amniotic fluid exert immunoregulatory function via secreted indoleamine 2,3-dioxygenase1. J. Cell. Mol. Med. 19, 1593-1605. doi: $10.1111 /$ jcmm. 12534

Ryan, J. M., Barry, F., Murphy, J. M., and Mahon, B. P. (2007). Interferon-gamma does not break, but promotes the immunosuppressive capacity of adult human mesenchymal stem cells. Clin. Exp. Immunol. 149, 353-363. doi: 10.1111/j. 1365-2249.2007.03422.x

Salvadori, M., Cesari, N., Murgia, A., Puccini, P., Riccardi, B., and Dominici, M. (2019). Dissecting the pharmacodynamics and pharmacokinetics of MSCs to overcome limitations in their clinical translation. Mol. Ther. Methods Clin. Dev. 14, 1-15. doi: 10.1016/j.omtm.2019.05.004
Sato, K., Ozaki, K., Oh, I., Meguro, A., Hatanaka, K., Nagai, T., et al. (2006). Nitric oxide plays a critical role in suppression of T-cell proliferation by mesenchymal stem cells. Blood 109, 228-234. doi: 10.1182/blood-2006-02-002246

Scarfe, L., Taylor, A., Sharkey, J., Harwood, R., Barrow, M., Comenge, J., et al. (2018). Non-invasive imaging reveals conditions that impact distribution and persistence of cells after in vivo administration. Stem Cell Res. Ther. 9:332. doi: 10.1186/s13287-018-1076-x

Seo, Y., Kim, H.-S., and Hong, I.-S. (2019). Stem cell-derived extracellular vesicles as immunomodulatory therapeutics. Stem Cells Int. 2019, 5126156. doi: 10. $1155 / 2019 / 5126156$

Serejo, T. R. T., Silva-Carvalho, A. É., Braga, L. D. C. F., Neves, F. A. R., Pereira, R. W., Carvalho, J. L., et al. (2019). Assessment of the immunosuppressive potential of INF- $\gamma$ licensed adipose mesenchymal stem cells, their secretome and extracellular vesicles. Cells 8:22. doi: 10.3390/cells8010022

Shahir, M., Mahmoud Hashemi, S., Asadirad, A., Varahram, M., Kazempour-Dizaji, M., Folkerts, G., et al. (2020). Effect of mesenchymal stem cell-derived exosomes on the induction of mouse tolerogenic dendritic cells. J. Cell. Physiol. 235, 7043-7055. doi: 10.1002/jcp.29601

Shao, L., Zhang, Y., Pan, X., Liu, B., Liang, C., Zhang, Y., et al. (2020). Knockout of beta-2 microglobulin enhances cardiac repair by modulating exosome imprinting and inhibiting stem cell-induced immune rejection. Cell. Mol. Life Sci. 77, 937-952. doi: 10.1007/s00018-019-03220-3

Shapouri-Moghaddam, A., Mohammadian, S., Vazini, H., Taghadosi, M., Esmaeili, S.-A., Mardani, F., et al. (2018). Macrophage plasticity, polarization, and function in health and disease. J. Cell. Physiol. 233, 6425-6440. doi: 10.1002/ jcp. 26429

Shen, B., Liu, J., Zhang, F., Wang, Y., Qin, Y., Zhou, Z., et al. (2016). CCR2 positive exosome released by mesenchymal stem cells suppresses macrophage functions and alleviates ischemia/reperfusion-induced renal injury. Stem Cells Int. 2016, 1240301. doi: 10.1155/2016/1240301

Shigemoto-Kuroda, T., Oh, J. Y., Kim, D. K., Jeong, H. J., Park, S. Y., Lee, H. J., et al. (2017). MSC-derived extracellular vesicles attenuate immune responses in two autoimmune murine models: type 1 diabetes and uveoretinitis. Stem Cell Rep. 8, 1214-1225. doi: 10.1016/j.stemcr.2017.04.008

Shojaati, G., Khandaker, I., Funderburgh, M. L., Mann, M. M., Basu, R., Stolz, D. B., et al. (2019). Mesenchymal stem cells reduce corneal fibrosis and inflammation via extracellular vesicle-mediated delivery of miRNA. Stem Cells Transl. Med. 8, 1192-1201. doi: 10.1002/sctm.18-0297

Silva, A. M., Teixeira, J. H., Almeida, M. I., Gonçalves, R. M., Barbosa, M. A., and Santos, S. G. (2017). Extracellular Vesicles: immunomodulatory messengers in the context of tissue repair/regeneration. Eur. J. Pharm. Sci. 98, 86-95. doi: 10.1016/j.ejps.2016.09.017

Song, T., Eirin, A., Zhu, X., Zhao, Y., Krier James, D., Tang, H., et al. (2020). Mesenchymal stem cell-derived extracellular vesicles induce regulatory $\mathrm{T}$ cells to ameliorate chronic kidney injury. Hypertension 75, 1223-1232. doi: 10.1161/ HYPERTENSIONAHA.119.14546

Song, Y., Dou, H., Li, X., Zhao, X., Li, Y., Liu, D., et al. (2017). Exosomal miR-146a contributes to the enhanced therapeutic efficacy of interleukin-1beta-primed mesenchymal stem cells against sepsis. Stem Cells 35, 1208-1221. doi: 10.1002/ stem. 2564

Spaggiari, G. M., Capobianco, A., Abdelrazik, H., Becchetti, F., Mingari, M. C., and Moretta, L. (2008). Mesenchymal stem cells inhibit natural killer-cell proliferation, cytotoxicity, and cytokine production: role of indoleamine 2,3dioxygenase and prostaglandin E2. Blood 111, 1327-1333. doi: 10.1182/blood2007-02-074997

Spinosa, M., Lu, G., Su, G., Bontha, S. V., Gehrau, R., Salmon, M. D., et al. (2018). Human mesenchymal stromal cell-derived extracellular vesicles attenuate aortic aneurysm formation and macrophage activation via microRNA-147. FASEB J. 32:fj201701138RR. doi: 10.1096/fj.201701138RR

Stephen, J., Bravo, E. L., Colligan, D., Fraser, A. R., Petrik, J., and Campbell, J. D. M. (2016). Mesenchymal stromal cells as multifunctional cellular therapeutics a potential role for extracellular vesicles. Transfus. Apher. Sci. 55, 62-69. doi: 10.1016/j.transci.2016.07.011

Svensson, K. J., Christianson, H. C., Wittrup, A., Bourseau-Guilmain, E., Lindqvist, E., Svensson, L. M., et al. (2013). Exosome uptake depends on ERK1/2-heat shock protein 27 signaling and lipid Raft-mediated endocytosis negatively regulated by caveolin-1. J. Biol. Chem. 288, 17713-17724. doi: 10.1074/jbc. M112.445403 
Szyska, M., and Na, I. K. (2016). Bone marrow GvHD after allogeneic hematopoietic stem cell transplantation. Front. Immunol. 7:118. doi: 10.3389/ fimmu.2016.00118

Takeda, K., Webb, T. L., Ning, F., Shiraishi, Y., Regan, D. P., Chow, L., et al. (2018). Mesenchymal stem cells recruit CCR2(+) monocytes to suppress allergic airway inflammation. J. Immunol. 200, 1261-1269. doi: 10.4049/jimmunol.1700562

Tavakoli, S., Zamora, D., Ullevig, S., and Asmis, R. (2013). Bioenergetic profiles diverge during macrophage polarization: implications for the interpretation of 18F-FDG PET imaging of atherosclerosis. J. Nucl. Med. 54, 1661-1667. doi: 10.2967/jnumed.112.119099

Teng, X., Chen, L., Chen, W., Yang, J., Yang, Z., and Shen, Z. (2015). Mesenchymal stem cell-derived exosomes improve the microenvironment of infarcted myocardium contributing to angiogenesis and anti-inflammation. Cell. Physiol. Biochem. 37, 2415-2424. doi: 10.1159/000438594

Théry, C., Witwer, K. W., Aikawa, E., Alcaraz, M. J., Anderson, J. D., Andriantsitohaina, R., et al. (2018). Minimal information for studies of extracellular vesicles 2018 (MISEV2018): a position statement of the International Society for Extracellular Vesicles and update of the MISEV2014 guidelines. J. Extracell. Vesicles 7:1535750. doi: 10.1080/20013078.2018.153 5750

Ti, D., Hao, H., Tong, C., Liu, J., Dong, L., Zheng, J., et al. (2015). LPSpreconditioned mesenchymal stromal cells modify macrophage polarization for resolution of chronic inflammation via exosome-shuttled let-7b. J. Transl. Med. 13:308. doi: 10.1186/s12967-015-0642-6

Tian, T., Zhu, Y. L., Zhou, Y. Y., Liang, G. F., Wang, Y. Y., Hu, F. H., et al. (2014). Exosome uptake through clathrin-mediated endocytosis and macropinocytosis and mediating miR-21 delivery. J. Biol. Chem. 289, 22258-22267. doi: 10.1074/ jbc.M114.588046

Toubai, T., Sun, Y., and Reddy, P. (2008). GVHD pathophysiology: is acute different from chronic? Best Pract. Res. Clin. Haematol. 21, 101-117. doi: 10. 1016/j.beha.2008.02.005

Tyndall, A., and Dazzi, F. (2008). Chronic GVHD as an autoimmune disease. Best Pract. Res. Clin. Haematol. 21, 281-289. doi: 10.1016/j.beha.2008.03.003

van den Akker, F., Vrijsen, K. R., Deddens, J. C., Buikema, J. W., Mokry, M., van Laake, L. W., et al. (2018). Suppression of T cells by mesenchymal and cardiac progenitor cells is partly mediated via extracellular vesicles. Heliyon 4:e00642. doi: 10.1016/j.heliyon.2018.e00642

van Hoeven, V., Munneke, J. M., Cornelissen, A. S., Omar, S. Z., Spruit, M. J., Kleijer, M., et al. (2018). Mesenchymal stromal cells stimulate the proliferation and IL-22 production of group 3 innate lymphoid cells. J. Immunol. 201, 1165-1173. doi: 10.4049/jimmunol.1700901

Ventura Ferreira, M. S., Bienert, M., Müller, K., Rath, B., Goecke, T., Opländer, C., et al. (2018). Comprehensive characterization of chorionic villi-derived mesenchymal stromal cells from human placenta. Stem Cell Res. Ther. 9:28. doi: 10.1186/s13287-017-0757-1

Wang, J., Ren, H., Yuan, X., Ma, H., Shi, X., and Ding, Y. (2018). Interleukin10 secreted by mesenchymal stem cells attenuates acute liver failure through inhibiting pyroptosis. Hepatol. Res. 48, E194-E202. doi: 10.1111/hepr.12969

Wang, L., Gu, Z., Zhao, X., Yang, N., Wang, F., Deng, A., et al. (2016). Extracellular vesicles released from human umbilical cord-derived mesenchymal stromal cells prevent life-threatening acute graft-versus-host disease in a mouse model of allogeneic hematopoietic stem cell transplantation. Stem Cells Dev. 25, 1874-1883. doi: 10.1089/scd.2016.0107

Wang, X., Gu, H., Qin, D., Yang, L., Huang, W., Essandoh, K., et al. (2015). Exosomal miR-223 contributes to mesenchymal stem cell-elicited cardioprotection in polymicrobial sepsis. Sci. Rep. 5:13721. doi: 10.1038/ srep13721

Ware, M. J., Tinger, S., Colbert, K. L., Corr, S. J., Rees, P., Koshkina, N., et al. (2015). Radiofrequency treatment alters cancer cell phenotype. Sci. Rep. 5:12083. doi: 10.1038/srep 12083

Wen, D., Peng, Y., Liu, D., Weizmann, Y., and Mahato, R. I. (2016). Mesenchymal stem cell and derived exosome as small RNA carrier and Immunomodulator to improve islet transplantation. J. Control. Release 238, 166-175. doi: 10.1016/j. jconrel.2016.07.044

Willis, G. R., Fernandez-Gonzalez, A., Anastas, J., Vitali, S. H., Liu, X., Ericsson, M., et al. (2017). Mesenchymal stromal cell exosomes ameliorate experimental bronchopulmonary dysplasia and restore lung function through macrophage immunomodulation. Am. J. Respir. Crit. Care Med. 197, 104-116. doi: 10.1164/ rccm.201705-0925OC
Woo, C. H., Kim, H. K., Jung, G. Y., Jung, Y. J., Lee, K. S., Yun, Y. E., et al. (2020). Small extracellular vesicles from human adipose-derived stem cells attenuate cartilage degeneration. J. Extracell. Vesicles 9:1735249. doi: 10.1080/20013078. 2020.1735249

Wu, X.-Q., Yan, T.-Z., Wang, Z.-W., Wu, X., Cao, G.-H., and Zhang, C. (2017). BM-MSCs-derived microvesicles promote allogeneic kidney graft survival through enhancing micro-146a expression of dendritic cells. Immunol. Lett. 191, 55-62. doi: 10.1016/j.imlet.2017.09.010

Xu, R., Zhang, F., Chai, R., Zhou, W., Hu, M., Liu, B., et al. (2019). Exosomes derived from pro-inflammatory bone marrow-derived mesenchymal stem cells reduce inflammation and myocardial injury via mediating macrophage polarization. J. Cell. Mol. Med. 23, 7617-7631. doi: 10.1111/jcmm.14635

Yang, Y., Hong, Y., Cho, E., Kim, G. B., and Kim, I.-S. (2018). Extracellular vesicles as a platform for membrane-associated therapeutic protein delivery. J. Extracell. Vesicles 7:1440131. doi: 10.1080/20013078.2018.1440131

Yen, B. L., Yen, M. L., Hsu, P. J., Liu, K. J., Wang, C. J., Bai, C. H., et al. (2013). Multipotent human mesenchymal stromal cells mediate expansion of myeloidderived suppressor cells via hepatocyte growth factor/c-met and STAT3. Stem Cell Rep. 1, 139-151. doi: 10.1016/j.stemcr.2013.06.006

Yu, B., Shao, H., Su, C., Jiang, Y., Chen, X., Bai, L., et al. (2016). Exosomes derived from MSCs ameliorate retinal laser injury partially by inhibition of MCP-1. Sci. Rep. 6:34562. doi: 10.1038/srep34562

Yuan, X., Li, D., Chen, X., Han, C., Xu, L., Huang, T., et al. (2017). Extracellular vesicles from human-induced pluripotent stem cell-derived mesenchymal stromal cells (hiPSC-MSCs) protect against renal ischemia/reperfusion injury via delivering specificity protein (SP1) and transcriptional activating of sphingosine kinase 1 and inhibiting necroptosis. Cell Death Dis. 8:3200. doi: 10.1038/s41419-017-0041-4

Yukawa, H., Watanabe, M., Kaji, N., Okamoto, Y., Tokeshi, M., Miyamoto, Y., et al. (2012). Monitoring transplanted adipose tissue-derived stem cells combined with heparin in the liver by fluorescence imaging using quantum dots. Biomaterials 33, 2177-2186. doi: 10.1016/j.biomaterials.2011. 12.009

Zaborowski, M. P., Balaj, L., Breakefield, X. O., and Lai, C. P. (2015). Extracellular vesicles: composition, biological relevance, and methods of study. Bioscience 65 , 783-797. doi: 10.1093/biosci/biv084

Zech, D., Rana, S., Büchler, M. W., and Zöller, M. (2012). Tumor-exosomes and leukocyte activation: an ambivalent crosstalk. Cell Commun. Signal. 10:37. doi: 10.1186/1478-811x-10-37

Zeiser, R., and Blazar, B. R. (2017). Acute graft-versus-host disease - biologic process, prevention, and therapy. N. Engl. J. Med. 377, 2167-2179. doi: 10.1056/ NEJMra1609337

Zhang, B., Yeo, R. W. Y., Lai, R. C., Sim, E. W. K., Chin, K. C., and Lim, S. K. (2018a). Mesenchymal stromal cell exosome-enhanced regulatory T-cell production through an antigen-presenting cell-mediated pathway. Cytotherapy 20, 687-696. doi: 10.1016/j.jcyt.2018.02.372

Zhang, B., Yin, Y., Lai, R. C., Tan, S. S., Choo, A. B. H., and Lim, S. K. (2013). Mesenchymal stem cells secrete immunologically active exosomes. Stem Cells Dev. 23, 1233-1244. doi: 10.1089/scd.2013.0479

Zhang, L., and Wang, C. C. (2014). Inflammatory response of macrophages in infection. Hepatobiliary Pancreat. Dis. Int. 13, 138-152. doi: 10.1016/s14993872(14)60024-2

Zhang, Q., Fu, L., Liang, Y., Guo, Z., Wang, L., Ma, C., et al. (2018b). Exosomes originating from MSCs stimulated with TGF- $\beta$ and IFN- $\gamma$ promote Treg differentiation. J. Cell. Physiol. 233, 6832-6840. doi: 10.1002/jcp.26436

Zhang, W., Ge, W., Li, C., You, S., Liao, L., Han, Q., et al. (2004). Effects of mesenchymal stem cells on differentiation, maturation, and function of human monocyte-derived dendritic cells. Stem Cells Dev. 13, 263-271. doi: 10.1089/ 154732804323099190

Zhao, H., Shang, Q., Pan, Z., Bai, Y., Li, Z., Zhang, H., et al. (2018). Exosomes from adipose-derived stem cells attenuate adipose inflammation and obesity through polarizing M2 macrophages and beiging in white adipose tissue. Diabetes 67, 235-247. doi: 10.2337/db17-0356

Zheng, Y., Dong, C., Yang, J., Jin, Y., Zheng, W., Zhou, Q., et al. (2019). Exosomal microRNA-155-5p from PDLSCs regulated Th17/Treg balance by targeting sirtuin-1 in chronic periodontitis. J. Cell. Physiol. 234, 20662-20674. doi: 10. 1002/jcp. 28671

Zhuansun, Y., Du, Y., Huang, F., Lin, L., Chen, R., Jiang, S., et al. (2019). MSCs exosomal miR-1470 promotes the differentiation of CD4+CD25+FOXP3+ 
Tregs in asthmatic patients by inducing the expression of P27KIP1. Int. Immunopharmacol. 7:105981. doi: 10.1016/j.intimp.2019.105981

Zou, X., Gu, D., Zhang, G., Zhong, L., Cheng, Z., Liu, G., et al. (2016). NK cell regulatory property is involved in the protective role of MSC-derived extracellular vesicles in renal ischemic reperfusion injury. Hum. Gene Ther. 27, 926-935. doi: 10.1089/hum.20 16.057

Zou, X., Zhang, G., Cheng, Z., Yin, D., Du, T., Ju, G., et al. (2014). Microvesicles derived from human Wharton's Jelly mesenchymal stromal cells ameliorate renal ischemia-reperfusion injury in rats by suppressing CX3CL1. Stem Cell Res. Ther. 5:40. doi: $10.1186 /$ scrt 428
Conflict of Interest: The authors declare that the research was conducted in the absence of any commercial or financial relationships that could be construed as a potential conflict of interest.

Copyright $\odot 2020$ Bazzoni, Takam Kamga, Tanasi and Krampera. This is an openaccess article distributed under the terms of the Creative Commons Attribution License (CC BY). The use, distribution or reproduction in other forums is permitted, provided the original author(s) and the copyright owner(s) are credited and that the original publication in this journal is cited, in accordance with accepted academic practice. No use, distribution or reproduction is permitted which does not comply with these terms. 